\title{
Postgenomic strategies in antibacterial drug discovery
}

\section{Heike Brötz-Oesterhel ${ }^{\dagger 1} \&$ Peter Sass ${ }^{2}$}

'AiCuris, Wuppertal, Germany

Institute of Medical Microbiology, Immunology \& Parasitology, Pharmaceutical Microbiology Section,

University of Bonn, Germany

†Author for correspondence: Institute for Pharmaceutical Biology, University of Duesseldorf, Universitätsstrasse 1. Building 26.23.U1, Germany = Tel. : +49 2118114180 m Fax: +49 2118111923 m heike.broetz-oesterhelt@ uni-duesseldorf.de

During the last decade the field of antibacterial drug discovery has changed in many aspects including bacterial organisms of primary interest, discovery strategies applied and pharmaceutical companies involved. Target-based highthroughput screening had been disappointingly unsuccessful for antibiotic research. Understanding of this lack of success has increased substantially and the lessons learned refer to characteristics of targets, screening libraries and screening strategies. The 'genomics' approach was replaced by a diverse array of discovery strategies, for example, searching for new natural product leads among previously abandoned compounds or new microbial sources, screening for synthetic inhibitors by targeted approaches including structure-based design and analyses of focused libraries and designing resistance-breaking properties into antibiotics of established classes. Furthermore, alternative treatment options are being pursued including anti-virulence strategies and immunotherapeutic approaches. This article summarizes the lessons learned from the genomics era and describes discovery strategies resulting from that knowledge.

This article is dedicated to Professor Dr Harald Labischinski in homage to his constant effort in the discovery and development of novel antibiotics.

\section{Antibiotic therapy under resistance pressure}

Since the 1940 s we have experienced the impressive potential of antibiotics in reducing morbidity and mortality thereby increasing the quality of life. However, over the last two decades this achievement is increasingly threatened by bacterial resistance development. Nowadays, infections caused by multidrug-resistant bacteria present daily challenges to infectious disease physicians in hospitals throughout the world and these pathogens are spreading into the community [1,2]. In developed countries, the most problematic bacterial species in terms of high incidence of infection, attributable morbidity and resistance factors undermining standard antibiotic therapy include methicillinresistant Staphylococcus aureus (MRSA), vancomycin-resistant Enterococcus, extended-spectrum $\beta$-lactamase producing Enterobacteriaceae, Pseudomonas aeruginosa and Acinetobacter baumannii [1-3]. Several treatment options currently exist for the Gram-positive pathogens from this list, which reflects the focused effort of antibiotic companies in this sector over the last decade. Drugs launched since 2000 (particularly linezolid, daptomycin, tigecycline and telavancin) plus the prospect of several additional agents in late-stage development (e.g., anti-MRSA cephalosporins, the glycopeptide-cephalosporin hybrid
TD-1792, the tetracycline derivative amadacycline, and a new streptogramine combination plus several quinolones and oxazolidinones [4]) have, for the time being, averted the immediate threat of MRSA. However, it is important that, with the exception of the lipopeptide daptomycin and the oxazolidinone linezolid, this list lacks further new antibiotic classes, for which there is still a high demand, and that there is also continued need for orally available drugs and bactericidal agents with good tissue penetration. In addition, it is noteworthy that several agents in development for the therapy of infections caused by multiresistant isolates have recently encountered difficulties in the regulatory approval process (e.g., ceftobiprole, iclaprim, oritavancin, dalbavancin, cethromycin), which will postpone or even prevent their market entries either worldwide or in particular countries.

Regarding Gram-negative pathogens, the current treatment situation is far more worrisome because new anti-Gram-negative agents are scarce in pharmaceutical pipelines and predominantly in early stages of development [4]. This asymmetry can, to a certain extent, be attributed to the fact that this bacterial spectrum had received less attention from the pharmaceutical industry from the mid-1990s onwards, but it is also important to bear in mind that it is much easier to discover novel agents with antibacterial activity against

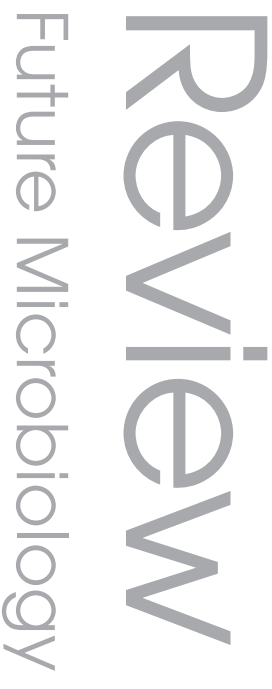

\section{Keywords}

- antibiotic = development - drug discovery - genomics - natural product = rational design $=$ resistance

n screening = structure " target

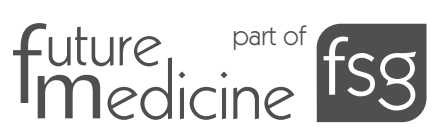


Gram-positive than against Gram-negative species and that nonfermenters are especially difficult to target. The outer membrane of Gram-negative bacteria plays an important role in this respect, because its penetration requirements are directly opposed to those of the cytoplasmic membrane. A broad collection of highly efficient efflux pumps further aggravates antibiotic attack. Based on our personal experience we estimate that, when screening random and unbiased libraries of diverse low molecular weight chemical entities, the hit rate for compounds with initial activity against Escherichia coli is 1-2 orders of magnitude lower than that for $S$. aureus, and for nonfermenters such as $P$. aeruginosa the yield is especially low. As a result, we have to cope with an increasing number of reports on infections caused by multidrug-resistant Gram-negative microorganisms for which antibacterial treatment options are very limited [5]. European surveillance data from 2008 indicate that $3.1 \%$ of invasive $E$. coli isolates and $14 \%$ of Klebsiella pneumoniae blood isolates showed combined resistance to fluoroquinolones, aminoglycosides and third-generation cephalosporins. Similarly, $17 \%$ of European $P$. aeruginosa isolates were shown to be resistant to three or more compounds or compound classes, respectively (including piperacillin/tazobactam, ceftazidime, carbapenems, fluoroquinolones and aminoglycosides) [201]. The recovery of $P$. aeruginosa isolates susceptible only to polymyxins from critically ill patients has left colistin as the only available therapy in these cases. It is characteristic of our current situation that we have no choice but treat these patients with a drug that had been shelved for decades due to strong nephrotoxicity and neurotoxicity and that would most probably never obtain regulatory approval by current standards. Even worse, outbreaks of colistin-resistant pandrug-resistant $P$. aeruginosa isolates have already been described [6,7]. Despite the rarity of isolation of pandrug-resistant Gramnegative bacteria so far, there is great concern, as clinicians are practically left with no treatment options for patients who carry these bacteria. Industry is aware of the urgent need for novel resistance breaking compounds against Gramnegative bacteria and among the companies that remained active in antibiotic research many shifted their present attention to the discovery of new anti-Gram-negative agents, which resulted in several distinct approaches in discovery and early development $[4,8]$.

We have to face the fact that bacterial resistance development and spread is an inevitable consequence of any antibiotic treatment. The very short generation times characteristic for bacteria facilitate development of resistance traits by a rapid mutation and selection process and the ability to disseminate genetic material across species borders promotes their spread [9]. In addition, versatile efflux pumps [10] and efficient penetration barriers [11], as well as the ability to react to antibiotic exposure by elaborate physiological responses in order to reduce the detrimental effects on cell structure and metabolism [12] constitute an impressive intrinsic defense strategy of bacteria against antibiotic attack. As a result, we cannot completely prevent the erosion of efficacy of our current antibiotic arsenal over time by bacterial resistance development [202], even by the most prudent application regimens or hygienic measures [9,13]. However, it should be emphasized that proper hygiene, skilful antibiotic treatment and restricted use play an important role, as obvious from the large geographic differences in resistance prevalence and that we need globally improved measures in order to prolong the lifespan of our current antibiotics [202]. However, even against our newest antibiotic classes resistance has already been reported, emphasizing the need for novel antibiotics (FIGURE 1) [14,15]. It is also crucial to bear in mind that bacterial resistance is not the only factor that defines medical need. Severe nosocomial infections in critically ill or immunocompromised patients can cause life-threatening illnesses and death, even if the causative pathogens fall below the susceptibility breakpoints of the applied antibiotics. In a situation where we face an aging, less immunocompetent patient population and where medical progress allows for treatments such as cancer chemotherapy and organ transplantation, we have additional need for highly effective, bactericidal and highly penetrative antibiotics that complement our current armamentarium. Therefore, the continuous discovery and development of novel antibacterial agents with unprecedented mechanisms of action devoid of cross-resistance to currently used antibiotics as well as the exploration of alternative treatment strategies are necessary to ensure efficient antibacterial therapy in the future.

\section{The classical approach: screening for whole-cell antibacterial activity}

Without exception, all currently used antibiotic classes were discovered through an empirical serendipitous approach by screening natural product extracts or synthetic compounds from various sources for promising antibacterial activity against bacteria of the desired spectrum. The vast majority 
of them were discovered in a highly productive period from the 1940s to the 1960s (Figure 1). Then a gap of almost four decades followed until the first representative of a new class entered the market in 2000. What happened in the meantime to prevent prolongation of this streak of success? One reason that is often forgotten is that the pharmaceutical industry was busy and productive in optimizing the originally discovered predecessor molecules and developed a multitude of considerably improved follow-up compounds that were superior with respect to efficacy, bacterial spectrum, tolerability and dosing interval. It cannot be denied that the perception of having basically solved the problem of bacterial infections together with commercial considerations as discussed below had triggered a decline in antibacterial research and development efforts. However, the hundreds of antibacterial natural products described in the scientific literature [16] demonstrate that considerable effort had continuously been invested into the discovery of new antibacterial lead structures. Such screening programs seem to have led either to the rediscovery of already known antibiotic classes or to compounds that were inferior in their overall profile or too complex for chemical modification at that time. One feasible explanation is that the low hanging fruit, that is to say, the natural product antibiotics that are readily produced under laboratory conditions by easily culturable organisms, had already been picked. Furthermore, regulatory demands on the efficacy and safety of new antibiotics have substantially increased over time, in parallel with the improved therapeutic standard and technical progress in measuring these parameters. As a result, the requirements that a new antibiotic chemical entity has to fulfill in order to obtain regulatory approval are much higher today than in the early days of antibiotic discovery and many agents that had been approved at that time would not be able to achieve this goal by current standards.

\begin{tabular}{|c|c|c|c|c|c|c|c|}
\hline \multirow[t]{6}{*}{ Introduction of neu } & antibiotic classes & $\begin{array}{l}1959 \\
\text { Nitroimidazoles }\end{array}$ & & & & \multirow{2}{*}{\multicolumn{2}{|c|}{$\begin{array}{l}\square \text { Derived from a natural product } \\
\square \text { Synthetic origin }\end{array}$}} \\
\hline & & $\begin{array}{l}1957 \\
\text { Ansamycins }\end{array}$ & & & & & \\
\hline & & $\begin{array}{l}1956 \\
\text { Glycopeptides }\end{array}$ & & & & & \\
\hline & $\begin{array}{l}1949 \\
\text { Chloramphenicol }\end{array}$ & $\begin{array}{l}1952 \\
\text { Macrolides }\end{array}$ & & & & & \\
\hline & $\begin{array}{l}1947 \\
\text { Nitrofuran }\end{array}$ & $\begin{array}{l}1952 \\
\text { Lincosamides }\end{array}$ & & & & & \\
\hline & $\begin{array}{l}1944 \\
\text { Aminoglycosides }\end{array}$ & $\begin{array}{l}1952 \\
\text { Streptogramins }\end{array}$ & $\begin{array}{l}1968 \\
\text { Trimethoprim }\end{array}$ & & & & $\begin{array}{l}2003 \\
\text { Lipopeptides }\end{array}$ \\
\hline $\begin{array}{l}1935 \\
\text { Sulfonamides }\end{array}$ & $\begin{array}{l}1941 \\
\beta \text {-lactams }\end{array}$ & $\begin{array}{l}1950 \\
\text { Tetracyclines }\end{array}$ & $\begin{array}{l}1962 \\
\text { Quinolones }\end{array}$ & & & & $\begin{array}{l}2000 \\
\text { Oxazolidinones }\end{array}$ \\
\hline $1930 \mathrm{~s}$ & 1940 s & $1950 s$ & $1960 s$ & 1970 s & $1980 s$ & $1990 \mathrm{~s}$ & $2000 s$ \\
\hline 更 & $\begin{array}{l}1940 \\
\text { Penicillinase } \\
1942 \\
\text { Sulfonamide } \\
\text { resistance } \\
1947 \\
\text { Streptomycin } \\
\text { resistance }\end{array}$ & $\begin{array}{l}1953 \\
\text { Macrolide } \\
\text { resistance }\end{array}$ & $\begin{array}{l}1961 \\
\text { Methicillin } \\
\text { resistance } \\
1966 \\
\text { Nalidixic acid } \\
\text { resistance } \\
1968 \\
\text { Tetracycline } \\
\text { resistance } \\
1969 \\
\text { Aminoglycoside- } \\
\text { modifying } \\
\text { enzymes }\end{array}$ & & $\begin{array}{l}1981 \\
\text { Amp C } \\
\beta \text {-lactamase } \\
1983 \\
\text { ESBL } \\
1986 \\
\text { VRE }\end{array}$ & $\begin{array}{l}\text { 1990s } \\
\text { Fluorochinolone } \\
\text { resistance } \\
1997 \\
\text { VISA }\end{array}$ & 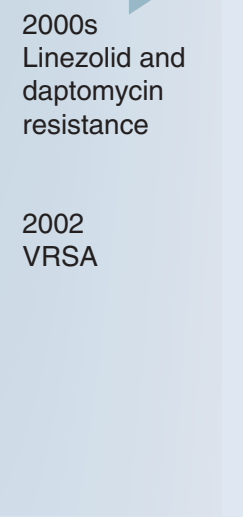 \\
\hline
\end{tabular}

Figure 1. Overview of systemically applied broad-spectrum antibiotic classes. The approximate year of introduction into human therapy is indicated along with concomitant occurrence of bacterial resistance.

ESBL: Extended spectrum $\beta$-lactamase; VISA: Vancomycin intermediately resistant Staphylococcus aureus; VRE: Vancomycin-resistant Enterococcus; VRSA: Vancomycin highly resistant Staphylococcus aureus. 


\section{The genomic approach: the unfulfilled promise}

The lack of success from screening of microbial extracts together with the discovery of the enormous potential of the synthetic quinolone class had led most pharmaceutical companies to redirect their screening efforts from natural product libraries to synthetic low molecular weight compounds. The enormous amount of bacterial genomic information, which has become available from 1995 onwards, triggered further major alterations in antibacterial screening strategies and led to the advent of the 'genomics era'. Today more than 1000 fully sequenced eubacterial genomes are available for comparative analyses in antibiotic drug discovery [203]. Rather than phenotypic screening for antibacterial activity, inhibition of rationally preselected targets was at that time considered to be the key to the identification of novel antibacterial lead structures. Central to this paradigm shift was the belief that bacteria would contain a rich number of hitherto unknown and therefore unexploited targets for antibiotic therapy, which were for the first time accessible by genome analysis. Bioinformatics was employed to compare the genomes of important bacterial pathogens and to contrast them with the available eukaryotic genomes. With the intention in mind to select targets that are broadly conserved among the desired bacterial spectrum but absent or evolutionary distant in eukaryotes, similar and often overlapping lists of potential target candidates were assembled by pharmaceutical companies, which represented in the range of 150-350 targets, depending on the broadness of the desired bacterial spectrum $[17,18]$. For target validation (Figure 2), the respective genes were then subjected to knockout analyses, mutation studies and inducible gene expression experiments to identify the targets that are essential for bacterial survival under in vitro growth conditions. Such experiments were often conducted for one Gram-positive and one Gram-negative model organism only, because the workload for mutating every target species of interest would have been enormous. Target proteins were then expressed, purified and screened, wherever possible under miniaturized high-throughput assay conditions, against libraries in the range of 1 million synthetic compounds, many of which had been obtained by combinatorial and parallel synthesis methods. At the time, considerable effort had been invested into the very first step of antibacterial drug discovery, that is to say, evaluating the quality of novel targets, but it turned out that this investment led to very limited success in identifying suitable leads for further optimization into antibacterial development candidates (FIgure 3).

Illustrative examples of large screening campaigns include those of GlaxoSmithKline (GSK) and Pfizer [17,19]. In the years 1995-2001, researchers from GSK had selected more than 350 genes of interest by comparative genome analyses of $S$. aureus, Streptococcus pneumoniae and Haemophilus influenzae. Of these, 127 were identified as being essential in at least one of these organisms and 67 were screened as purified proteins in high-throughput screening (HTS) against the corporate compound collection, which ranged from 260,000 to 530,000 compounds. Of these 67 assays, only 16 yielded hits, five of them resulted in leads and only one lead series was progressed to development; the fatty acid biosynthesis inhibitor series, which relies on FabI (enoyl-acyl carrier protein [ACP] reductase) as the target [17]. However, as the enoylACP reductase function is performed in several important pathogens by enzymes unrelated to FabI (e.g., FabK in S. pneumoniae [20], or FabV in $P$. aeruginosa [21]), this target is only suitable for a narrow spectrum approach and the resulting inhibitor was outlicensed by GSK to the biotech company Affinium. Their candidate AFN-1252 is currently being developed for oral treatment of $S$. aureus infections and Phase I studies were initiated in March 2008. Similarly, Pfizer reported that only four leads resulted from 65 HTS campaigns and that none of them was developed to the point of reaching clinical trials [19]. In a somewhat different approach, Cubist had concentrated on one specific target class, which they explored extensively [22]. They predominantly focused on aminoacyl-tRNA synthetases and of the 20 representatives of this target family, which are all indispensable for bacterial survival, they screened 17 enzymes against a rather small library of 50,000 compounds, also without success. Other companies including Wyeth, Bristol Meyers Squibb or Bayer HealthCare had comparable experiences with their target-related HTS approaches, which led to the industry-wide conclusion that it made little scientific or economic sense to simply keep screening more targets in the same manner. Why was the success rate so low in relation to the enormous effort invested into this screening strategy?

\section{Lessons learned from the genomics era}

Over the years considerable knowledge has accumulated that explains why the target-based HTS approach was not as successful as anticipated. 


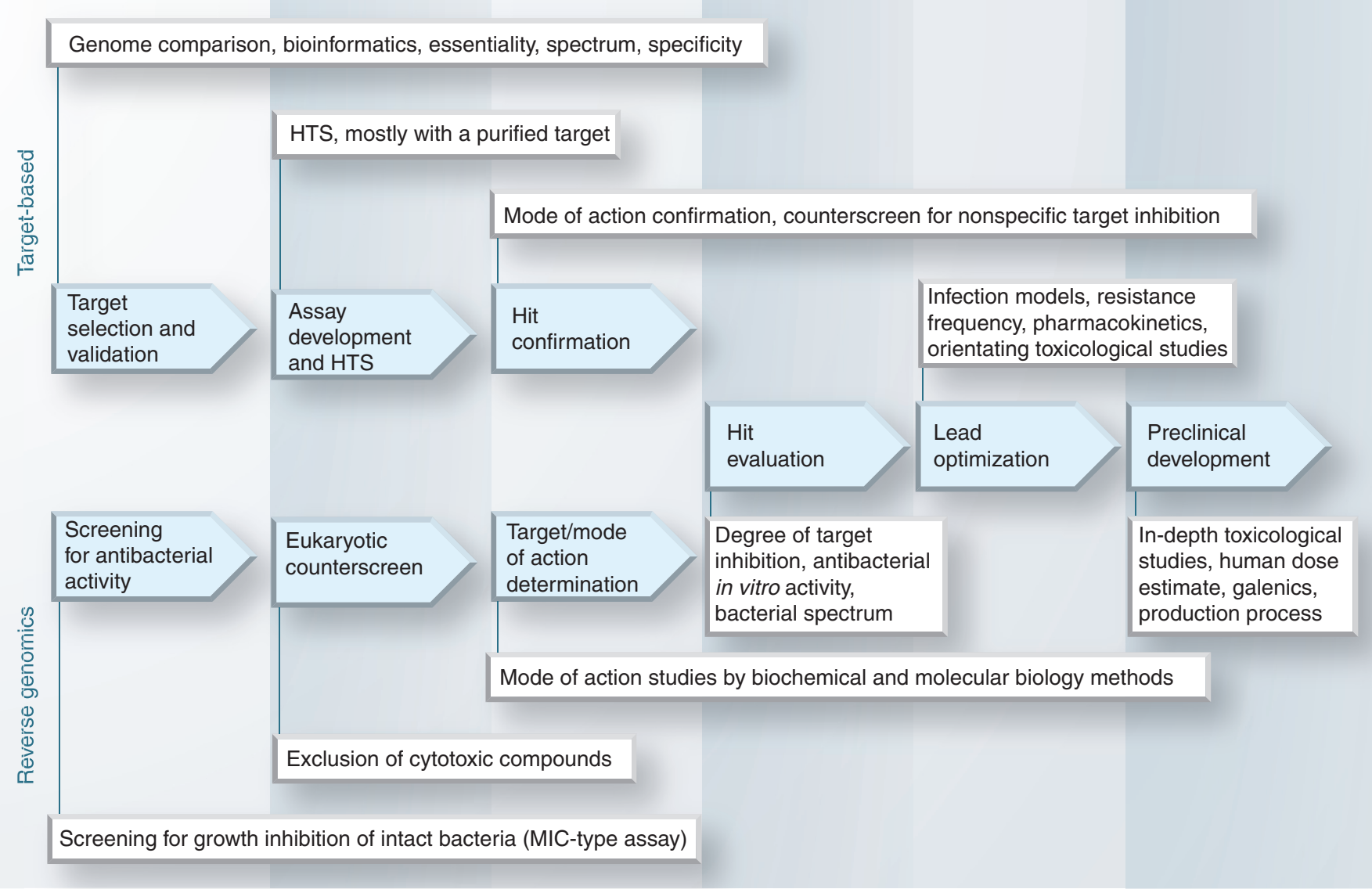

Figure 2. The antibacterial drug discovery process. In the search for novel antibiotic classes, two prominent strategies have been followed over the last decade: the genomics approach starting from an unprecedented rationally selected target and an alternative approach starting from a compound with interesting antibacterial activity. For the latter approach, the term reverse genomics had been coined to indicate that the genomic target is identified only in a second step. Due to the aid of powerful functional genomics techniques, the speed of target identification has considerably improved and in most cases the target is known at the start of a lead structure optimization program. From in-depth hit evaluation onwards both approaches are processed similarly. HTS: High-throughput screen; MIC: Minimal inhibitory concentration.

The reasons are related to the targets themselves and their selection procedure, the screening process and the compound pools employed as source of inhibitors.

\section{Lessons from targets}

The first explanation lies in the targets themselves. The previous perception that there would be a wealth of novel and unexplored broad-spectrum targets, which could be easily exploited for antibiotic therapy, turned out to be wrong. Apart from the characteristics used for target selection (i.e., target conservation, evolutionary distance to human homologs and reduction of in vitro growth rate upon target depletion), a target has to possess several further equally important prerequisites (Box 1). It is absolutely essential that the target is not only mandatory for bacterial survival in vitro but also in the nutrient-rich environment of the human body and that the bacteria have no mechanism for circumventing the target reaction by acquiring its reaction product from the host. An illustrative example is fatty acid biosynthesis, which had been heavily investigated during the genomics era and resulted in leads such as AFN-1252 (GSK/Affinium) [23], platensimycin (Merck) [24], platencin (Merck) [25] and the pyrrolidine diones (Bayer) [26]. Interestingly, later studies revealed that major low-GC Gram-positive pathogens are resistant to fatty acid biosynthesis inhibitors in vitro, when their culture broth is supplemented with unsaturated exogenous fatty acids in the concentration that is present in human serum or when human serum is added [27]. Along the same line, infectivity of Streptococcus agalactiae mutants in mice was not diminished by the deletion of essential fatty acid biosynthesis genes, thereby questioning the need for de novo fatty acid biosynthesis under in vivo infection conditions in compartments where exogenous fatty acids are present [27]. It is also crucial that antibiotics have a low propensity to select for resistant mutants 


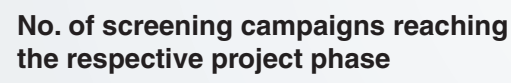

Molecular target (enzyme)

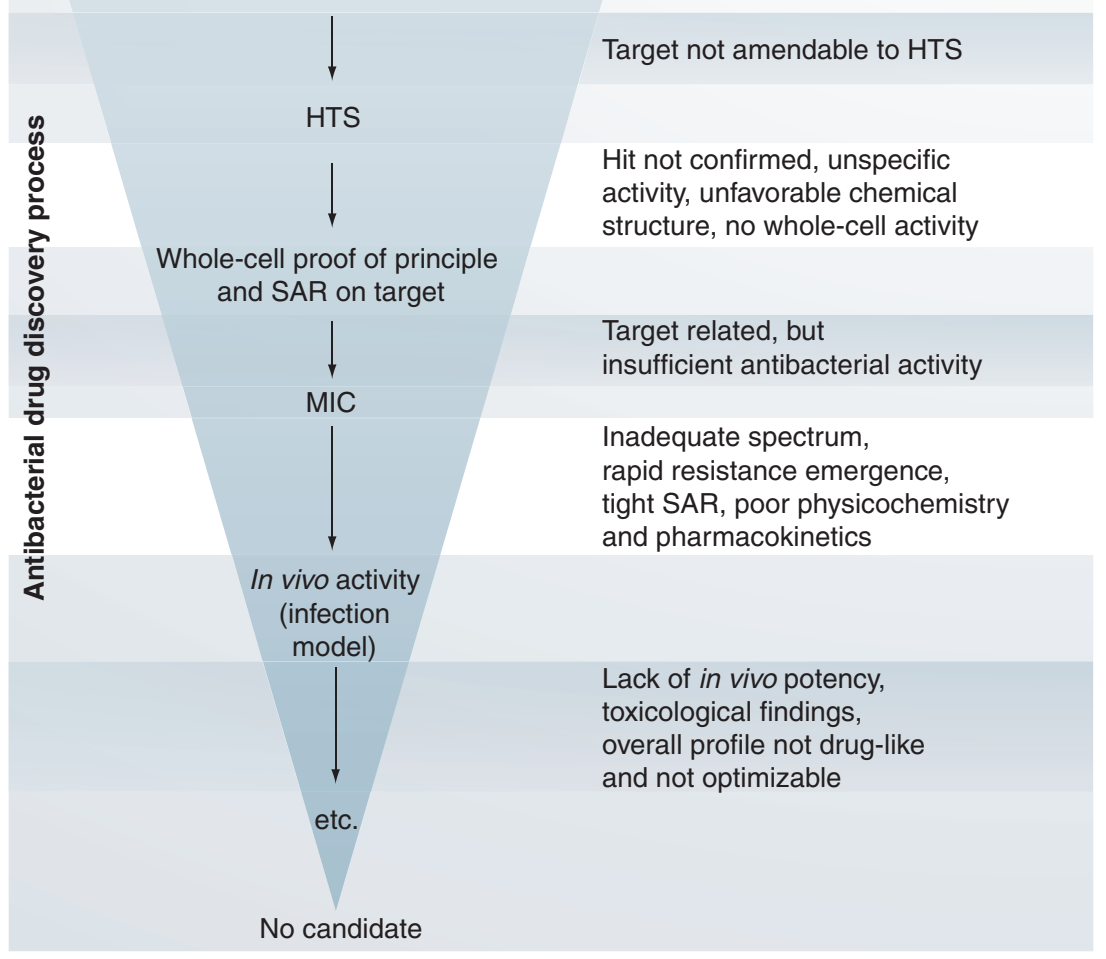

Figure 3. High attrition rates in target-based high-throughput screening and reasons for failures at the different stages of the profiling cascade. HTS: High-throughput screening; MIC: Minimal inhibitory concentration; SAR: Structure-activity relationship.
Reasons for drop-out from cascade activity, unfavorable chemical structure, no whole-cell activity

Target related, but

Inadequate spectrum, tight SAR, poor physicochemistry and pharmacokinetics

Lack of in vivo potency,

icological findings,

overall profile not drug-like

and not optimizable

within a bacterial population, which means that point mutations in the target gene must not allow for a noteworthy increase in MIC. Indeed, all antibiotics that have been successfully applied in systemic monotherapy for many years do not rely on single targets or on targets that are encoded by a single gene $[28,29]$. An additional aspect is that for full coverage of the desired bacterial spectrum the target has to be validated for each and every bacterial species in vitro as well as in the infection model. Targets can encode an essential function in one organism but can be dispensable in another by means of a biochemical bypass reaction or redundant enzyme equipment. The enoyl-ACP reductase mentioned above is one example, as it is encoded by distinct isoforms (FabI, FabK, FabL, $\mathrm{FabV}$ ) in different bacterial species with varying sensitivity for known fatty acid biosynthesis inhibitors $[20,21,30]$. To complicate the situation further, genetic diversity might even occur for different strains within the same species. When researchers from GSK investigated quinolinone derivatives as exploratory inhibitors of methionyl-tRNA synthetase in a panel of 101 clinical S. pneumoniae

isolates, they observed that $20 \%$ were intrinsically resistant to their antibiotic due to the presence of a second unrelated methionyl-tRNA synthetase [31]. Knowing these potential pitfalls is a first important step, but this does not solve the problem of identifying novel broad-spectrum targets of high quality. Validation of the essential nature of a previously uninvestigated target for all species of the intended bacterial spectrum in vitro as well as in the host during the infection process is mandatory and methodologically highly challenging, especially if at the beginning of a screening campaign a model target inhibitor is not available. Techniques for in vivo target validation have been described but only sporadically applied [32,33]. This makes targets and metabolic pathways that have been validated by therapeutically applied antibiotics especially valuable. Along the same line, an analysis of genes expressed by Salmonella enterica in a mouse model of typhoid fever revealed that almost all of the in vivo expressed and essential genes are either absent in other pathogens, thus limiting their usefulness as broad-spectrum targets, or belong to pathways already addressed by current antibiotics or development compounds [34]. A further lesson that can be learned from therapeutically proven antibiotics is that complex mechanisms (e.g., by interfering with more than a single target or inhibiting a target in a different way than simply preventing its catalytic function) seem beneficial for exerting bactericidal activity [28].

\section{Lessons from screening strategies \\ \& screening libraries}

The targets are only one part of the problem. The assay set-up and screening strategies applied play another important role. When isolated targets are screened in cell-free biochemical assay formats, penetration through the bacterial cell envelope is not a selection criterion for hits. As a result, a large percentage of the hits obtained will not be able to enter the cell and, consequently, will not exert antibacterial activity [17]. A way to overcome this is the design of whole-cell assays that allow for measurement of the function of the desired target in the intact bacterial cell. This can be achieved, for instance, on the basis of the differential sensitivity of target-depleted strains. The target might either be silenced by antisense RNA [35,36] or be downregulated by expression behind a regulated promoter [37]. In both cases an inhibitor of the desired target will display differential antibacterial activity against mutant versus wild-type strain. The charm of these methodologies is that they can, in principle, be 
applied to the analysis of all gene-encoded targets. The drawback is that two detection points (i.e., mutant plus wild-type) are required for each time point and inhibitor concentration, doubling the screening effort. A further technical limitation during HTS is that the inhibitor concentration needs to fall in the range where it prevents growth of the mutant but not yet that of the wild-type and that hitting this often small detection window cannot be guaranteed for all compounds from a large library. Another interesting strategy for whole-cell screening is to go beyond the single target to the analysis of metabolic pathways and target areas. Our knowledge on bacterial regulons responding to certain types of metabolic disturbances including antibiotic attack is constantly growing [12] and examples have been described where this information was exploited for the construction of bacterial reporter strains that reacted to drug-induced inhibition of certain target areas by emission of a luminescent signal [38-40].

Although initial knowledge gaps have probably led to early mistakes in certain cases, such as insufficiently validating unprecedented targets or choosing suboptimal screening strategies, this does not explain the industry-wide lack of success of almost all antibacterial high-throughput target-based campaigns. When natural product libraries were screened with the same assays, proofof-principle was obtained that known natural product inhibitors of given targets or target areas could successfully be detected [39]. So, why were novel chemical entities suitable as starting points for antibacterial drug discovery so rarely discovered in the large 'big-pharma' screening libraries? The problem resides within the compound collections themselves. It is now widely acknowledged that the characteristics of antibiotics differ in important aspects from those of drugs in other therapeutic sectors, such as cancer, cardiovascular, metabolic or central nervous system diseases and in particular that parenteral antibiotics do not follow the Lipinski's 'rule of five' [41-43]. In general, the chemical structures of antibiotics are more complex than those of drugs marketed in other fields and contain more stereocenters, rotatable bonds, proton donors and acceptors and, often, multiple pharmacophores. As far higher serum and tissue concentrations are needed for efficient treatment of bacterial infections than for obtaining pharmacological effects in other disease areas, it is also important that antibiotics possess sufficient solubility and free fractions (i.e., the compound amount that is not tightly bound to serum components such as albumine or $\alpha$-glycoprotein) to achieve these drug levels. This necessity plus the penetration requirements of the bacterial cell envelope lead to a physicochemical profile that significantly differs from that of other drugs (Figure 4) [42]. In general, antibiotics are less lipophilic than other drugs and higher molecular weights are tolerated for compounds that target extracytoplasmic structures of Gram-positive bacteria. The dilemma is that the distribution of physicochemical parameters of the big-pharma compound libraries follows the average needs of all therapeutic sectors, with the result that only a rather small subset of screening compounds has a profile suitable for antibacterials. HTS will only be capable of identifying compounds that already exist in corporate collections. Increasing understanding of this problem has, in recent years, led to the conclusion that antibacterial screening approaches should rather be based on focused libraries, with more natural product-like physicochemical properties [17,44].

A probable additional counterproductive aspect was the managerial attitude that dominated the high-throughput era. High attrition rates of early hits and leads were expected from this approach, as it relied strongly on quantity and the philosophy was to terminate presumably unsuccessful projects very rapidly. As a result, the periods companies allowed for compound optimization were often too short to meet the substantial optimization requirements of antibacterial leads.

\section{Box 1. Lessons learned from the} high-throughput screening era.

\section{The targets}

Targets need to be validated in every species (pay attention to subpopulations).

Targets need to be validated in vivo.

Single gene targets are prone to rapid resistance development.

Antibacterial polypharmacology (multiple targets, multiple binding sites) is beneficial. Complex mechanisms, rather than simple inhibition of enzyme function, seem more efficient in achieving bactericidal activity.

Therapeutically validated targets are especially valuable.

\section{The assay formats}

Screens against isolated targets often yield hits without cell penetration.

MIC assays often yield nonspecific compounds. Whole-cell assays increase the chance of specific membrane permeable hits (drawback: limited detection window).

\section{The compounds}

Large 'big-pharma' compound libraries contain few antibiotic-like structures.

Physicochemistry of antibacterials is different. 


\section{Postgenomic approaches}

When companies realized that the HTS campaigns as described above make little sense in antibacterial research, substantial shifts in the field occurred. Several big players left the whole area of antibiotic research for economic reasons, as discussed briefly below, mid-sized spin-offs were formed from bigpharma research units that developed products of their parent companies further and a variety of novel biotechnology companies were founded to seize the opportunity of reduced competition. Today, there is no longer a predominant research strategy followed by most, rather, diverse and complementary approaches are being pursued, some of them new, others well-known but technically improved. Several such strategies are illustrated by selected examples in TABre 1 and corresponding compound structures are depicted in Figure 5. Although this collection gives a good impression of the current strategies that are applied in the search for novel antibiotics, it should be noted that this compilation is only exemplary and that there is no claim of completeness, neither in terms of research programs that have been or still are being pursued, nor with regard to compound classes or inventing companies. For the leads, development candidates or launched products provided as examples, the focus here is on the strategy that led to their discovery. For their status within the discovery or development process, their intended indication as well as strengths and potential weaknesses, the interested reader is referred to other excellent reviews $[4,41,45,46]$.

\section{Natural product research}

When the small molecule synthetics failed to deliver suitable leads for antibacterial drug discovery, interest in natural products flared up again [46-49]. This is not astonishing, since approximately $3 / 4$ of all currently used antibiotic classes originate from natural products (FIGURe 1). Although the reasons why natural products are

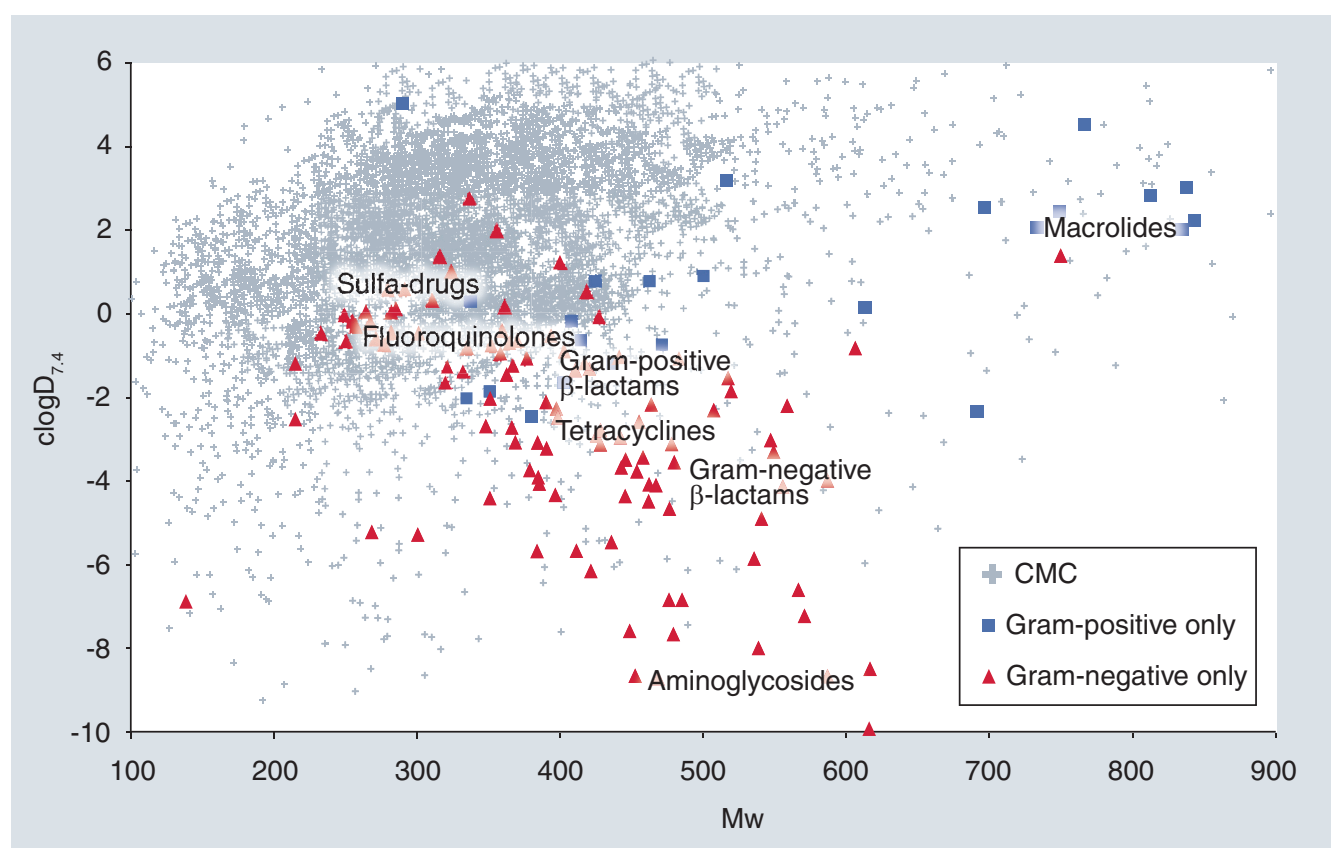

Figure 4. Physicochemistry of antibiotics compared with drugs in other therapeutic sectors. Comparing a set of 147 antibacterial compounds to 4623 compounds from the commercially available CMC database reveals major differences between antibiotics and 'other' drugs but also between antibacterial agents that target Gram-positive compared with Gram-negative bacteria. Antibiotics with exclusive activity against Gram-positive bacteria have much less restriction in molecular weight than other drugs, while antibiotics directed against Gram-negative species demonstrate a remarkable polarity. It seems that in order to penetrate the Gram-negative cell envelope and to efficiently evade efflux either highly polar compounds or zwitterionic compounds (as in the case of sulfa-drugs and quinolones), which are capable of changing their charge states in the process of crossing the two membranes, are required. It is reasonable to suggest that passage through a polar porin of the outer membrane is more efficient for a polar compound, while penetration of the cytoplasmic membrane can be achieved by passive diffusion in a nonpolar state, active uptake or forced entry of highly cationic compounds (e.g., the proton motive force-dependent self-driven uptake of highly charged aminoglycosides).

CMC: Comprehensive Medicinal Chemistry; Mw: Molecular weight.

Adapted with permission from [42]. Copyright (c) 2008 American Chemical Society. 
advantageous compared to synthetics in antibacterial drug discovery are not fully understood, it is obvious that natural products strongly surpass synthetics in terms of structural diversity, functional complexity and unique molecular architectures [41]. Their antibacterial activity surpasses that of synthetic screening hits in most cases, which is no wonder considering that antibiotic-producing strains have co-evolved over millions of years with other microorganisms in competition for the same ecological niche. In addition, complex mechanisms of action have often developed, which are multilayered, directed against more than a single target and would probably not have been invented by rational design. Plausible calculations in expert reports led to the conclusion that we have so far discovered only a small percentage of all antibacterial agents that are produced by microbial communities in diverse habitats world wide [47,50]. The majority of the antibacterials known to date are produced by rather easily culturable Streptomyces species and even among the streptomycetes a large pool of additional antibiotics can still be expected [47]. Therefore, one reasonable strategy towards future antibiotic drugs is the search for novel natural product leads by improved modern technologies. New habitats are currently being explored and innovative culture conditions are being developed to promote the growth of previously unculturable organisms [51,52]. An interesting pilot study demonstrated that the growth of previously unculturable organisms could be supported by culturing them together with other species from their natural habitat [53]. Modern molecular biology now allows the heterologous expression of foreign biosynthetic gene clusters in hosts that can be cultured more easily and even DNA pools of whole environmental communities are investigated by metagenomic techniques [47]. It can be expected that in the long term such methodical advances will uncover unexplored microbial sources and provide interesting new antibacterial lead structures, although the effort that has to be invested will remain higher than in the early days of antibacterial drug discovery, when there was still a choice of easily accessible antibacterial classes and when regulatory standards were lower.

To fill the medium term gap in their antibiotic pipelines, in the late 1990 s companies decided to revisit their already available libraries of natural product extracts or to mine the scientific literature for so far under-evaluated natural products. TABLE 1 provides several examples of structural classes that emerged from that effort. Wyeth, for instance, initiated a program, in which they re-investigated shelved fractions of their own natural product collection, which had been previously discarded due to narrow spectrum activity. From a fraction of Streptomyces hygroscopicus LL-AC98 they obtained the glycopeptide class of mannopeptimycins. The antibiotic complex of this strain had been known at Wyeth since the 1950s and was described in 1970 [301], but structure elucidation was only performed at the beginning the 2000s [54]. Components of the natural product complex showed interesting antibacterial activity against MRSA and penicillin-resistant streptococci and moderate activity against VRE [55]. Subsequently semisynthetic analogues were developed with improved enterococcal activity and safety profiles [56]. Mannopeptimycins inhibit peptidoglycan synthesis at the level of transglycosylation by targeting the membrane-bound precursor lipid II, but their binding site differs from that of vancomycin, which explains their activity against VRE [57].

Another novel natural product that addresses the same target is the peptide antibiotic plectasin that was isolated by Novozymes from the saprophytic fungus Pseudoplectania nigrella [58]. The structure of the oligopeptide plectasin ( 40 amino acids) closely resembles that of defensins from invertebrates [58]. However, in contrast to many other defensins, which according to current knowledge are believed to act rather nonspecifically at the level of the cytoplasmic membrane by dissipating the membrane potential or by interfering with the structure and function of diverse membrane-associated components [59], plectasin has a defined prokaryotic target, namely lipid II $[59,60]$. Like the mannopeptimycins, plectasin binds to lipid II in a region other than the D-alanyl-D-alanine terminus, thereby retaining activity against vancomycin-resistant isolates. While the natural product plectasin showed rather low activity against staphylococci, a recently reported derivative, NZ2114, displayed improved activity against staphylococci, while retaining its good activity against streptococci $[61,62]$. Apart from the proof that new interesting natural products can still be found, the two examples of the mannopeptimycins and plectasins teach a lesson with respect to antibacterial targets. Both classes confirm that it is possible to obtain resistance-breaking qualities by addressing a novel binding site at a therapeutically validated target and they highlight the value of natural products as tool compounds in target validation and identification. The lipodepsipeptide friulimicin, which was discovered by Hoechst Marion Roussel in 2000 [63], also has 


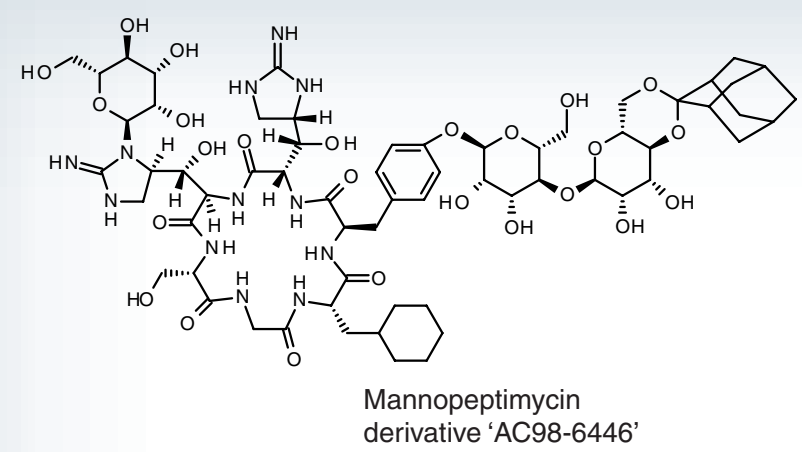

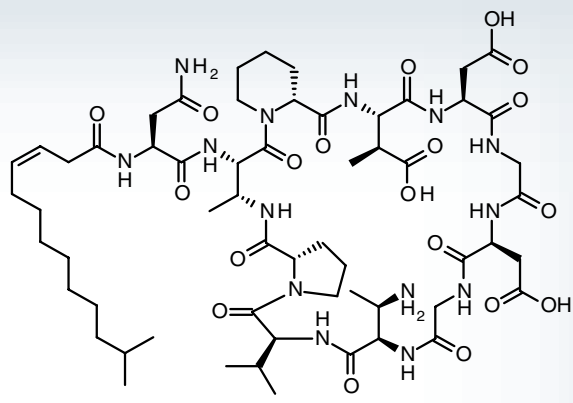

Friulimicin B $\overbrace{0}^{1}$

AFN-1252

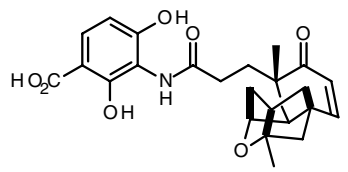

Platensimycin<smiles>CN(C(=O)C[C@H](N)CCCCCN)C1CNC(NC(N)=O)=NC1=O</smiles>

Tan 1057 derivative 'BRAM26'

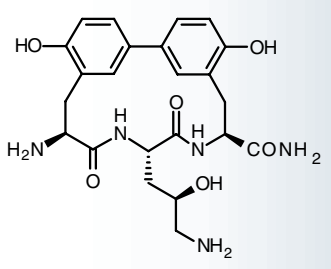

Biphenomycin B derivative 'WSF22'<smiles>N#Cc1ccc(/C=C/C(=O)NC(CC(=O)NC2C(=O)NC(=O)SC3CCCC32)c2ccccc2)cc1</smiles>

Moiramide B derivative<smiles>CCCCC=CC(=O)N[C@@H](Cc1cc(F)cc(F)c1)C(=O)NC(CCOC(=O)C1CC(C)CN1C(=O)C(C)NC(=O)C1CCCCN1C1CCCC1)C(=O)N1CCCC1</smiles>

ADEP derivative 'ADEP 4'

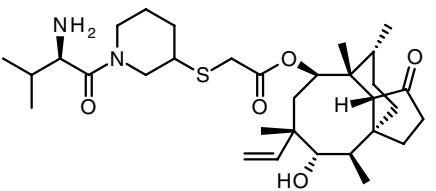

Pleuromutilin 'BC-3205'

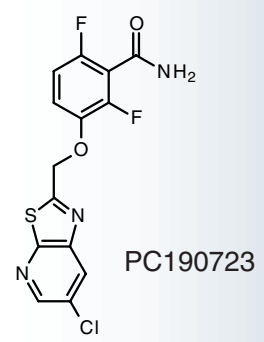

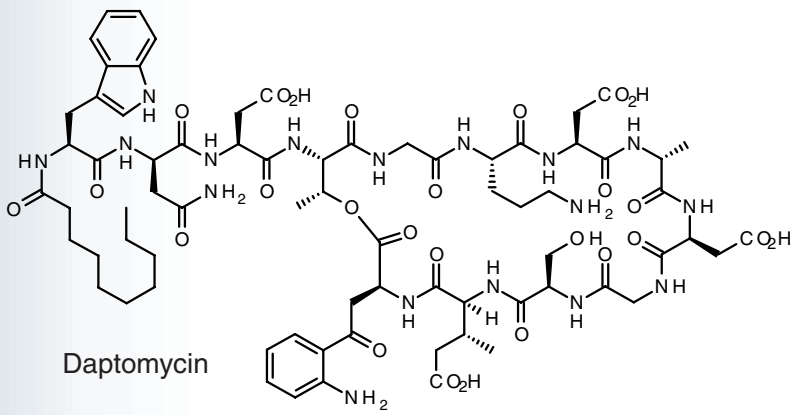

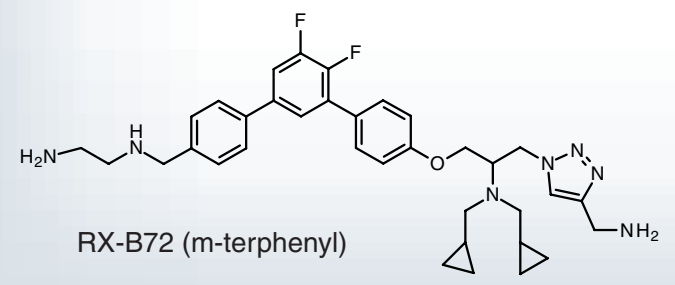

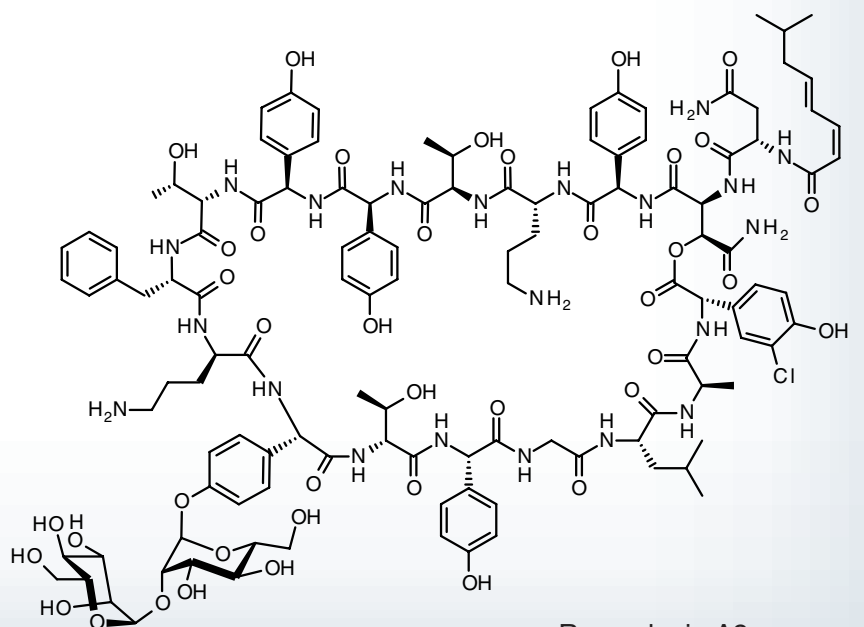

Ramoplanin A2

an interesting Gram-positive resistance-breaking spectrum and was recently shown to have an unprecedented target within the therapeutically validated target area of peptidoglycan synthesis. Friulimicin binds to undecaprenyl-pyrophosphate, thereby sequestering the bacterial lipid carrier and preventing its function in the synthesis of peptidoglycan and wall teichoic acids [64].

In a similar attempt to make use of their existing natural product library, Merck re-screened its 
<smiles>COc1cc(Cc2cnc(N)nc2N)c2c(c1OC)O[C@H](C1CC1)C=C2</smiles>

Iclaprim<smiles>Cc1[nH]c(C(=O)N[C@H]2CCN(c3nc(C(=O)O)cs3)C[C@@H]2F)c(Cl)c1Cl</smiles>

Exemplary pyrrolamide

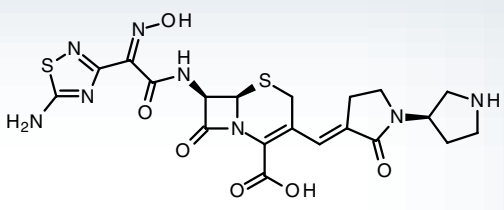

Ceftobiprole (active moiety Bal9141)<smiles>CN(C)c1cc(NC(=O)CNC(C)(C)C)c(O)c2c1C[C@H]1C[C@H]3[C@H](N(C)C)C(O)=C(C(N)=O)C(=O)[C@@]3(O)C(O)=C1C2=O</smiles>

Tigecycline

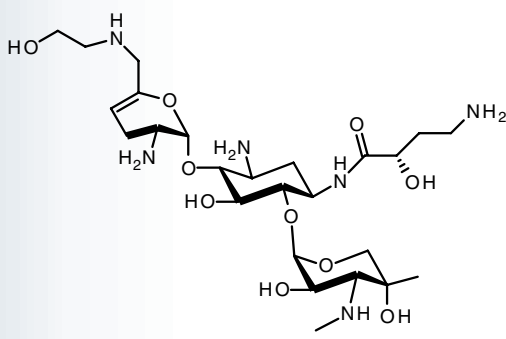

ACHN-490

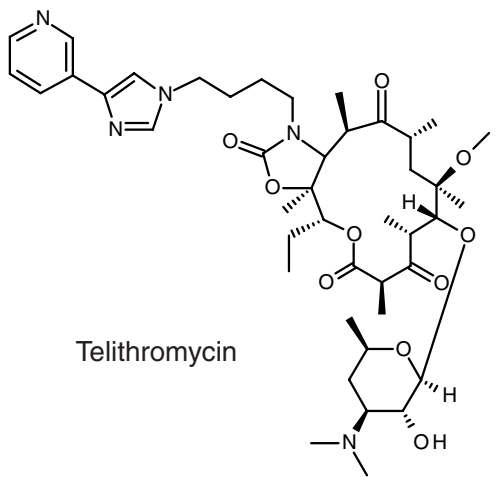<smiles></smiles>

BAL 30072

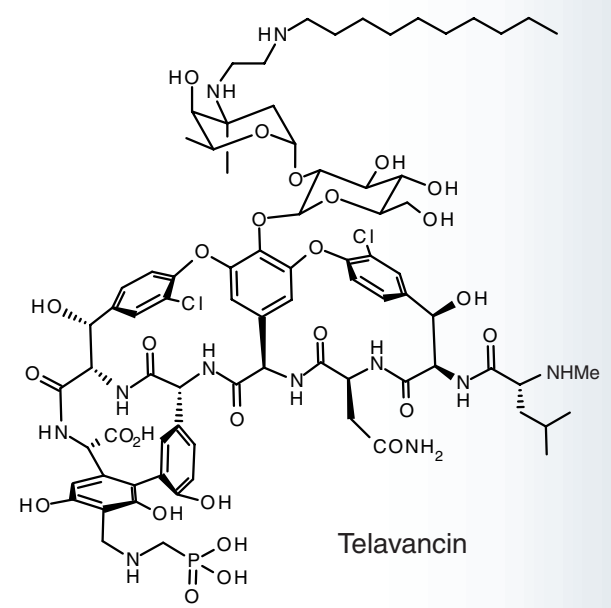<smiles>Cn1nnc(-c2ccc(-c3ccc(N4C[C@H](CO)OC4=O)cc3F)cn2)n1</smiles>

(active moiety TR-700)

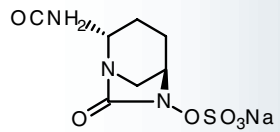

NXL 104<smiles>Nc1nc(-n2cc(C(=O)O)c(=O)c3cc(F)c(N4CC(O)C4)c(Cl)c32)c(F)cc1F</smiles>

Delafloxacin (ABT-492)<smiles>C[C@H]1CCc2c(N3CCC(O)CC3)c(F)cc3c(=O)c(C(=O)O)cn1c23</smiles>

WCK 771<smiles>Cc1c(N2C[C@@H]3NCCO[C@H]3C2)c(F)cc2c(=O)c(C(=O)O)cn(C3CC3)c12</smiles>

Finafloxacin<smiles>CC(=O)c1ccc(/C=C/C(=O)Nc2ccc(-c3nc4ccc([N+](=O)[O-])cc4n3[O-])cc2)cc1</smiles>

P005784

Figure 5. Selected antibiotics discussed in this article (cont.).

culture extract collection for inhibitors of selected targets using RNA silencing in intact bacterial cells. In an assay in which antisense RNA of a key enzyme in fatty acid biosynthesis (the ketoacyl-ACP synthase II [FabF]), was expressed in
S. aureus in order to make FabF rate-limiting for cellular survival, they discovered platensimycin [24,65]. The compound inhibited FabF isolated from $S$. aureus with an $\mathrm{IC}_{50}$ of $48 \mathrm{nM}$ by binding to the acyl-enzyme intermediate formed in the 
Table 1. Selected prominent examples of postgenomic strategies for the discovery of novel antibiotics.

\section{Discovery approach \\ Compound class (examples)}

\section{Antibiotic strategies}

Screening for novel natural products

Re-evaluation of underexploited natural products

Structure-based drug design (new classes)

Optimization of established classes
Mannopeptimycins

Plectasins (NZ2114)

Friulimicin

CB-182804 (undisclosed lipopeptide)

Platensimycin, platencin

Tetrahydropyrimidinones

(Tan 1057, NP)

Biphenomycins

(biphenomycin B, NP)

Pyrrolidine diones

(moiramide $B, N P$ )

ADEPs (A54556 A, NP)

Daptomycin

Ramoplanin

Pleuromutilin

(BC-3205)

m-terphenyls

(RX B72)

PC 190723 series

Pyrrolamides

Anti-MRSA cephalosporins

(ceftobiprole, ceftaroline)

Tetracyclines (tigecycline, amadacycline)

Ketolides (telithromycin)

Glycopeptides (telavancin, oritavancin)
Compound origin Target

Lipid II

Lipid II

Undecaprenyl-diphosphate

Unknown

FabF

Ribosomal peptidyltransferase Bayer center

Novel target in translation, undisclosed

Acetyl-CoA carboxylase

Clp protease

Bacterial cytoplasmic membrane/ envelope Lipid II

Unmodified natural product

Natural product derivative

Synthetic, rational design A-site, 50 S ribosomal subunit

Synthetic, rational design FtsZ

Synthetic, rational design GyrB
Established natural
product-derived class

Established natural product-derived class

Established natural product-derived class

Established natural product-derived class

Penicillin-binding proteins including PBP2a

16S rRNA at A-site with additional contacts

23S rRNA domain V plus II

Lipid II, D-ala-D-ala terminus, plus additional interactions (interpeptide bridge, cytoplasmic membrane or penicillin-binding proteins)

Diamino-pyrimidines (iclaprim) Oxazolidinone (torezolid)

Quinolones (delafloxacin, WCK-771, finafloxacin)

Neoglycosides (ACHN-490)

Monobactams (BAL30072)
Established natural product-derived class

Synthetic, natural product origin
Synthetic, rational design Synthetic

Synthetic

Dihydrofolate reductase 23S rRNA at ribosomal A-site Topoisomerases II and IV

16S rRNA close to A-site

Penicillin-binding protein 3 plus 2
Companies

Wyeth

Novozymes/Sanofi-

Aventis

Hoechst/CombiNature/ MerLion

Cubist

Merck

Bayer/AiCuris

Bayer/InterMed

Discovery

Bayer/AiCuris

Cubist

Biosearch Italia/

Genome Therapeutics/ IntraBiotics/Oscient/

Nanotherapeutics

Nabriva

\section{Rib-X}

Prolysis

AstraZeneca

Basilea/Johnson \& Johnson, Forest

Wyeth, Paratek/Bayer/ Novartis

Hoechst/Sanofi-Aventis

Theravance/Astellas, Lilly/InterMune/

Targanta/The

Medicines Company

Roche/Arpida

Dong-A/Trius

Wakunaga/Abbott/

Rib-X, Wockhardt,

Combinature/MerLion

Achaogen

Basilea

KPC: Klebsiella pneumoniae carbapenemase; MRSA: Methicillin-resistant Staphylococcus aureus; NP: Natural product. 
Table 1. Selected prominent examples of postgenomic strategies for the discovery of novel antibiotics (cont.).

\begin{tabular}{|c|c|c|c|c|}
\hline $\begin{array}{l}\text { Discovery } \\
\text { approach }\end{array}$ & $\begin{array}{l}\text { Compound class } \\
\text { (examples) }\end{array}$ & Compound origin & Target & Companies \\
\hline \multicolumn{5}{|c|}{ Nonantibiotic strategies } \\
\hline $\begin{array}{l}\text { Inhibition of } \\
\text { resistance factors }\end{array}$ & Efflux pump inhibitors & Synthetic & $\begin{array}{l}\text { Efflux pumps } \\
\text { (e.g., AcrAB-TolC, } \\
\text { Mex-pumps) }\end{array}$ & Mpex \\
\hline \multirow[t]{2}{*}{ Virulence inhibition } & $\begin{array}{l}\text { Mar regulon inhibitors } \\
\text { (P005784) }\end{array}$ & Synthetic & $\begin{array}{l}\text { Resistance factor and } \\
\text { virulence factor expression }\end{array}$ & Paratek \\
\hline & $\begin{array}{l}\text { Inhibitors of teichoic acid and } \\
\text { lipopolysaccharide synthesis }\end{array}$ & Synthetic & Virulence factor expression & Mutabilis \\
\hline $\begin{array}{l}\text { Biologicals as } \\
\text { antibacterial agents }\end{array}$ & $\begin{array}{l}\text { Therapeutic antibody fragment } \\
\text { (KB001, KBPA 101, } \\
\text { pagibaximab) }\end{array}$ & $\begin{array}{l}\text { Natural product } \\
\text { derivatives }\end{array}$ & $\begin{array}{l}\text { Virulence factor } \\
\text { antagonization }\end{array}$ & $\begin{array}{l}\text { e.g., KaloBios, Kenta } \\
\text { Biotech, Biosynexus, } \\
\text { Medarex }\end{array}$ \\
\hline Immunostimulation & $\begin{array}{l}\text { Mimics/derivatives of host } \\
\text { defense peptides }\end{array}$ & $\begin{array}{l}\text { Natural product } \\
\text { derivatives }\end{array}$ & $\begin{array}{l}\text { Innate immunity, immune- } \\
\text { regulatory cascades }\end{array}$ & $\begin{array}{l}\text { e.g., Migenix, Genaera, } \\
\text { Ardea, AM-Pharma, } \\
\text { Inimex }\end{array}$ \\
\hline
\end{tabular}

course of the condensation reaction. MICs are in the low $\mu \mathrm{g} / \mathrm{ml}$ range for staphylococci, streptococci and enterococci. In vivo activity was reported in the treatment of a disseminating $S$. aureus infection in mice, although a continuous infusion regimen had to be applied in order to demonstrate this effect $[24,66]$. All of these examples are against Gram-positive bacteria only. However, first discovery approaches are now also being reported for Gram-negative bacteria. Cubist, for instance, has reported the development of a membrane-active lipopeptide (CB-182804) with bactericidal activity against Pseudomonas, Acinetobacter, Escherichia and Klebsiella. The compound is currently in Phase I trials for parenteral therapy of multidrugresistant Gram-negative bacteria, but to our best knowledge, details about structure and profile have not been disclosed.

Other companies such as Bayer put an effort into the in-depth investigation of previously described but underexploited natural products [41]. After literature mining, several natural product complexes were selected, for which interesting antibacterial activities had been previously reported, but which had been rather poorly characterized otherwise (TaBLe 1). Bayer employed functional genomics technologies such as proteomics and transcriptional profiling $[67,68]$ in combination with a versatile methodical platform for mode of action studies to elucidate their mechanisms. Two novel classes of translation inhibitors were identified. The dihydropyrimidinones derived from the natural product Tan-1057 bind to the large ribosomal subunit and inhibit the peptidyltranferase reaction [67,69] and the biphenomycins interfere with bacterial protein synthesis by another mechanism without cross-resistance to known translation inhibitors [41]. Furthermore, the pseudopeptide pyrrolidine diones, based on the natural product moiramide $B$, address a new target in fatty acid biosynthesis, the acetyl coenzyme A carboxylase [26]. In addition, a group of acyldepsipeptides designated ADEPs work by dysregulating the Clp protease and initiate bacterial death by degradation of essential bacterial proteins [70,71]. Despite the complexity of the molecules, routes for total syntheses were elaborated in all cases [41], thus, allowing broad compound derivatization using current medicinal chemistry technology. After detailed biological evaluation of the natural products, their weaknesses were addressed in optimization programs. For the pyrrolidine diones and the ADEPs, antibacterial activities were remarkably increased reaching MIC values of 0.01 and $0.05 \mu \mathrm{g} / \mathrm{ml}$, respectively, for $S$. aureus and 0.25 and $0.02 \mu \mathrm{g} / \mathrm{ml}$, respectively, for $S$. pneumoniae [72,73]. For both classes, physicochemical properties were improved in parallel and, in the case of the ADEPs also chemical and metabolic stability [72,73]. For the biphenomycins it was possible to improve antibacterial in vitro activity [41] and in the dihydropyrimidinone class, target-related toxicity could be reduced. While the natural product Tan-1057 
bound with similar affinities to prokaryotic and eukaryotic ribosomes [69], new derivatives demonstrated improved selectivity indices during in vitro transcription/translation in parallel with lower cytotoxicity against eukaryotic cells and improved tolerability in mice [41,74]. In the course of the optimization programs all four classes had in vitro and in vivo antibacterial activities against important Gram-positive pathogens well in the range of marketed antibiotics, without being affected by pre-existing cross-resistances. These examples demonstrate that previously described compound classes also bear considerable potential that can be exploited when investigating and improving these leads with current technologies.

The marketed drug daptomycin (Cubist) is another interesting example of a natural product that had long been neglected, but which has now found a highly successful application. Eli Lilly and Co., discovered daptomycin in the late 1980s [75] and initiated clinical trials for the treatment of Gram-positive infections, applying $3 \mathrm{mg} / \mathrm{kg}$ every $12 \mathrm{~h}$. When transient skeletal muscle myopathy was observed during Phase I trials, Lilly discontinued all development efforts. The drug remained unused for several years until Cubist licensed the compound and discovered that it was surprisingly well tolerated after once daily dosing, which allows the muscles sufficient time for recovery between two applications [76]. When the drug was launched in 2003 for the treatment of complicated skin and soft tissue infections by Gram-positive bacteria at $4 \mathrm{mg} / \mathrm{kg} / \mathrm{day}$ to be applied in a single $30 \mathrm{~min}$ infusion, it addressed a substantial medical need and became a commercial success. Along the same line the glycodepsipeptide ramoplanin A2 is another 'old' natural product that was discovered in 1984 by Biosearch Italia [77]. The compound has substantial activity against the most important Gram-positive pathogens including staphylococci, streptococci, enterococci and clostridia and a convincing target, again, lipid II. However, due to the lack of a suitable formulation for intravenous application and no oral bioavailability, the drug was shelved until the beginning of this decade and then passed through several biotech companies. At present, the unmodified natural product is being developed by Nanotherapeutics and is expected to enter Phase III trials for the oral treatment of Clostridium difficile-associated diarrhea, an indication where lack of oral bioavailability is an advantage. In addition, injectable formulations are under investigation [302] and a derivatization program on the basis of a successful total synthesis explores the chance of improved derivatives
[78]. A third prominent case of a long-neglected natural product class is that of the pleuromutilins, a family of protein synthesis inhibitors that bind to the peptidyl transferase center on the $50 \mathrm{~S}$ ribosomal subunit in a region partly overlapping with both A-site and P-site, thereby blocking peptide bond formation [79]. The natural product pleuromutilin was discovered in 1950 and a derivative, tiamulin, was approved for veterinary use in 1979. However, for human therapy the first representative of this class, retapamulin (GSK) was only introduced in 2007. Due to low oral bioavailability and insufficient metabolic stability, retapamulin is restricted to topical use but a new congener suitable for oral application (BC-3205) is currently being investigated in Phase I clinical trials by Nabriva [80].

Although the various examples presented here prove the potential of natural products for current antibacterial drug discovery, the risks of this approach are also important to consider. Apart from the positive characteristics of natural product antibacterials as described above, there are additional important factors, which are no optimization parameters during natural evolution, but which are indispensable for a successful drug (e.g., safety/tolerability, chemical and metabolic stability, human pharmacokinetics, producibility and cost of goods). Consequently, many natural products require extensive optimization prior to development, which is an often arduous and sometimes impossible task. Obtaining sufficient material for in-depth lead profiling can be a hurdle at the beginning of a new discovery program, when fermentation yields are still low. A laborious route for total synthesis may need to be developed prior to a meaningful optimization program. Complex synthetic access may limit the number of derivatives that can be explored and high production costs may exclude the use of the drug in certain indications. As a result, several of the examples discussed above have limitations that seem to have prevented their progression beyond their current state. Platensimycin has insufficient metabolic stability, friulimicin demonstrated unfavorable human pharmacokinetics in Phase I studies, the ADEPs have a rather high potential for resistance induction, the pyrrolidine dione class demonstrates only moderate in vivo activities and for the dihydropyrimidinones no progress was reported for years. Although natural product research is one prominent pillar of postgenomic antibacterial research, it is important that complementary strategies are followed in parallel, as described in the following section. 


\section{Structure-based design \& focused synthetic approaches}

Methodical advances in x-ray crystallography, nuclear magnetic resonance spectroscopy and computational tools made a significant contribution to the technical progress in antibacterial drug discovery. Over the last decade, not only the genes but also the structures of a large number of antibacterial targets became available and often structures of target protein homologues were solved for several bacterial species, offering comparison and broader applicability during modeling studies. Structures with high impact for antibacterial drug discovery include those of several topoisomerases, RNA polymerase, a large array of aminoacyltRNA synthetases, peptide deformylase, diverse ribosomal regions, various cytoplasmic and membrane-bound enzymes of peptidoglycan biosynthesis, diverse metabolic enzymes (e.g., those involved in fatty acid and isoprenoid biosynthesis) and cell division machinery (for a constantly updated overview see, for example, the protein database [204]). Importantly, not only the structures of the target apo-proteins were solved, but often also co-structures with substrates, reaction intermediates and inhibitors (including known antibiotics, hits, leads and exploratory tool compounds), thereby generating valuable information on active site topology, drugable regions and pharmacophore structure. This information is increasingly used in antibacterial drug discovery and the recent literature contains a variety of examples where structure-based design was employed by industry and academia for the identification of hits and lead structures from new structural classes as well as for the optimization of established antibiotics [81,82]. The structures are employed in different discovery strategies, including virtual screening of commercial or virtual compounds, fragment-based screening, de novo compound design on the basis of target substrates, products or reaction intermediates as well as for guiding chemistry campaigns by HTS. In addition, for interesting compounds discovered by empirical medicinal chemistry programs the co-structure with the target is often determined in the course of the project in order to understand the binding mode, to rationalize the structure-activity relationship (SAR) and to pave the road for further compound optimization. It is beyond the scope of this article to discuss the technical details, strengths and limitations of these approaches and for further information on these aspects the reader is directed to [44,83-86]. Instead, selected important cases will be described here, which exemplify the application of these techniques in the search for novel antibacterial agents.
Rational design was, for example, instrumental in the discovery of iclaprim, the successor of trimethoprim within the therapeutically established class of diaminopyrimidine antibiotics. Iclaprim had been investigated by Arpida in Phase III clinical trials for the treatment of staphylococcal skin and skin-structure infections [87] but failed to meet the noninferiority standards in the US FDA regulatory process. Trimethoprim is a competitive inhibitor of dihydrofolate reductase (DHFR), thereby preventing the biosynthesis of tetrahydrofolate, an essential cofactor in several one-carbon transfer reactions. A single amino acid exchange in the active site of $S$. aureus DHFR (F98Y) results in the loss of a crucial hydrogen bond between trimethoprim and its target and forms the main cause of trimethoprim resistance in this species [88]. Structural information from a trimethoprim-S. aureus DHFR co-crystal [88] and thorough understanding of the resistance mechanism was used by Roche in modeling studies with the aim to design diaminopyrimidines with improved activity against the DHFR of Gram-positive bacteria [89]. In iclaprim, which resulted from this effort, the trimethoxyphenyl side chain of trimethoprim is replaced by a dimethoxychromene substituent. This enlarged moiety allows for additional hydrophobic interactions with the target and a general gain of binding energy, resulting in a 20-fold higher affinity of iclaprim compared with trimethoprim at wild-type level ( $\mathrm{K}_{\mathrm{i}} 0.3$ and $6 \mathrm{nM}$, respectively) [90]. When the F98Y mutation occurs, target affinity of both inhibitors decreases by the same factor (20-fold, $\mathrm{K}_{\mathrm{i}}=6 \mathrm{nM}$ and $100 \mathrm{nM}$, respectively). However, according to the principle that potency may beat resistance, iclaprim still maintains low inhibition constants and corresponding MICs in the low $\mu \mathrm{g} / \mathrm{ml}$ range, while the MICs for trimethoprim are far beyond therapeutic concentrations [90].

In another program focused on rational design, Rib-X used high-resolution crystal structures of known protein biosynthesis inhibitors bound to the bacterial ribosome as a molecular framework for the design of new antibacterial scaffolds, which competed with the established antibiotics for target interaction. They discovered a series of m-terphenyls including RX-B72, which bind to the ribosomal A-site in a region that largely overlaps with the oxazolidinone binding site. The best compounds from that series demonstrated single-digit MIC values against important Gram-negative pathogens [91].

In efforts to develop novel FtsZ inhibitors undertaken by Prolysis, the template for rational design was not provided by an established 
antibiotic but by a small exploratory compound, almost devoid of antibacterial activity. FtsZ can be regarded as the pacemaker protein for cell division in bacteria. It is structurally and functionally homologous to mammalian tubulin and undergoes GTP-dependent polymerization at mid-cell at the time of cell division to form a ring structure that recruits further cell division proteins [92]. If the activity of Fts $\mathrm{Z}$ is disturbed, including its ability to interact with its partners, cell division is prevented leading to cell mass increase and eventually cell lysis. The simple structure of 3-methoxybenzamide (3-MBA) was selected as a starting point for the program. It had previously been reported to inhibit FtsZ and to induce filamentation in Bacillus subtilis as a proof of target inhibition in the intact bacterial cell [93]. Although 3-MBA possesses only marginal antibacterial activity (MIC against $B$. subtilis $=4000 \mu \mathrm{g} / \mathrm{ml}$ ), its principle ability to enter Gram-positive cells, its small size, which leaves room for compound expansion, and its corresponding high ligand efficacy (i.e., the free energy of binding per heavy atom) made it an attractive starting point for inhibitor design [94,95]. Classical exploration of the SAR around 3-MBA was supported by docking studies on the basis of the crystal structure of the FtsZ apoprotein from $B$. subtilis and by mutational analyses. The ligand was predicted to bind to a cleft adjacent to the GTP binding site of FtsZ and all mutations, obtained by selecting $S$. aureus resistant against an improved congener from the program, mapped to this region. On the basis of the suggested docking model, the small 3-MBA nucleus was grown in size and yielded PC190723 as the most progressed congener reported from this program so far [94,95]. In PC190723, the 3-methoxy group is replaced by a thiazolopyridine ring attached to the benzamide via an ether bridge. The activity of the compound is almost exclusively focused on staphylococci, with MICs of $0.5-1 \mu \mathrm{g} / \mathrm{ml}$ and moderate efficacy in a murine model of systemic staphylococcal infection. Further optimization is necessary, because in vivo efficacy is still 10 -fold inferior to vancomycin and a resistance rate of $2 \times 10^{-8}$ impedes use of the compound in monotherapy.

In cases where a suitable chemical structure that could serve as starting point for a structuredriven approach is not available, fragment-based screening is an option [44,96]. This technique is starting to show its potential in the first development compounds now entering clinical trials, however, these are in areas other than antibacterial research. Abbott is a pioneer in this technology, other companies have integrated it as a part of their discovery platform and AstraZeneca has reported using it in diverse disease areas including antibacterial lead discovery [44]. The central idea of the fragment-based approach is to screen a comparably small library (in the range of 1000 compounds) of low molecular weight synthetic structures (typically 150-250 Da) for inhibitors that bind to the target of interest. The use of structurally diverse generic synthetic libraries has been reported here with the option to extract a suitable subset of structures for a particular screening program, as well as the design of tailored libraries that exploit already available structural information of a particular target family (e.g., kinases). In the library design for their antibacterial fragment-based screening program, AstraZeneca took care to ensure that not only the molecular weight was lower than in their corporate collection used for HTS but also the clogP (the decadic logarithm of the calculated distribution coefficient between octanol and water), which is used as a measure for lipophilicity, and the nonpolar surface area, reflecting the potential for hydrophobic interactions with the target. Subsequently, this design allowed the addition of hydrophobic substituents to the fragments, which is a common strategy in medicinal chemistry for increasing binding affinity, without exceeding the upper limit of preferred logP. One technical challenge is that due to their limited size the initial fragments have comparably low binding affinities (in the $0.1-10 \mathrm{mM}$ range) and that the screening method has to be able to detect such weak binders reliably. Biophysical methods are often used here, such as nuclear magnetic resonance, surface plasmon resonance or thermal shift assays, which rely on the change in temperature that occurs when a target slightly unfolds upon fragment binding. Biochemical assays can also be used, if they are robust enough to allow extension of the inhibitor concentration to the $\mathrm{mM}$ range and if control assays are run in parallel to correct for potential artifacts (e.g., compound autofluorescence and quenching effects). Once binders with suitable affinities are identified, their co-structures with the target guide further optimization programs. Here, the method of expanding the nucleus of a single fragment by growing it within the binding site has so far been more successful than attempts to join two neighboring fragments, because it proved rather difficult to find suitable linkers that retained the optimal orientation and position of the two fragments [44,96]. As a result of this effort, AstraZeneca reported a pyrrolamide series as novel inhibitors of the DNA-gyrase $\beta$-subunit. In recent derivatives, a bis-chlorinated pyrrolamide is linked to a carboxy-thiazolyl moiety 
via a fluoro-piperidine linker. Most potent representatives displayed bactericidal activity with sub- $\mu \mathrm{g} / \mathrm{ml} \mathrm{MIC}_{90}$ values against $S$. pneumoniae, H. influenzae and Moraxella catarrhalis. However, in vivo efficacy requires further improvement [97,98]. The described examples demonstrate that there are alternatives to classical HTS for the discovery of novel inhibitors of bacterial targets and, due to the smaller number of compounds that need to be processed, more attention can be paid to the compilation of screening libraries as well as to the assay setup, which has to comply with medium-throughput requirements only. Structure-based design has proven instrumental in improving potency and selectivity at the target level, but as the conditions that mediate compound uptake through the bacterial cell envelope and that prevent efflux are still incompletely understood; rational design with respect to the latter features is not possible at present. Furthermore, it is obvious that a given structure has to succeed with regard to a variety of further parameters including pharmacokinetics, tolerability and bioavailability. Experience has taught that, using our current methodology, attempts to combine these disparate features into novel exploratory classes are not always successful. Therefore, it is also of high importance that we keep searching for novel resistance-breaking structures within known antibiotic classes that have already proven their therapeutic potential.

Optimizing established antibiotic classes Several companies have explored the option of introducing novel structural elements into established antibiotics with the aim of improving activities against wild-type strains and resistant isolates. The detailed knowledge of class- and compound-specific characteristics, a profound understanding of the SAR and in many cases molecular information of target-inhibitor interactions are advantages during the optimization of established classes. In fact, most antibiotics that are currently in the later stages of pharmaceutical development pipelines originate from these efforts, which proves the importance of this approach [4]. Here, resistance was circumvented by, for example:

- Increasing affinity for an as yet unaffected protein of a target family (e.g., ceftaroline and ceftobiprole) [99,100];

- Increasing affinity to the original target by establishing additional interactions with the target site or neighboring regions (e.g., iclaprim, torezolid, tigecycline, amadacycine) [89,101-103];
- Including a further binding domain at the same target (e.g., telithromycin, oritavancin) [103-105];

- Introducing an additional mode of action into the antibiotic (e.g., telavancin) [106];

- Evading bacterial efflux pumps (e.g., tigecycline, amadacycline) [107,108].

Interesting examples in earlier stages of the antibacterial drug discovery chain include two compounds with activity against multi-resistant Gramnegative isolates. The neoglycoside ACHN-490 (Phase I) was modified to resist attack by almost all aminoglycoside-degrading enzymes and the monobactam BAL-30072 (preclinical) benefits from facilitated uptake into bacterial cells via a siderophore mechanism and from increased stability against certain $\beta$-lactamases [109-112]. For most of these molecules potency was already improved at the susceptible wild-type level and although target-related resistance mutations do often also affect these new derivatives of known classes, their activity seems high enough to maintain therapeutic efficacy against a large proportion of currently resistant isolates. Aside from the examples listed above, the same principle of 'potency beats resistance' applies to the new quinolones in development (e.g., delafloxacin and WCK 771), which demonstrate good activity against quinoloneresistant Gram-positive bacteria, especially staphylococci, although the mechanistic basis for this potency increase is less understood due to the lack of target co-structures [113,114]. This general increase of wild-type activity is beneficial in severely ill patients, where highly effective antibiotics are necessary. Another quinolone in development, finafloxacin, relies entirely on the concept of improved activity under infection conditions [115]. While the compound is slightly inferior to established quinolones in standard MIC determinations that are performed at neutral $\mathrm{pH}$, its activity surpasses that of all other marketed quinolones in acidic environments, for example the gastrointestinal or urogenital tract, or during infection conditions that are accompanied by acidification of the environment.

\section{Alternative treatment strategies \& narrow spectrum therapy}

Apart from the antibiotic approach that relies on an active small molecule that inhibits bacterial growth, a variety of further treatment principles are currently being explored by industry and academia. Extension beyond the scope of classical antibiotics can be envisaged in several ways, either by leaving the requirement of 
direct bacterial growth inhibition, by leaving the realm of small molecules, or even by shifting the focus of therapeutic intervention completely away from the invading bacterial pathogen to stimulation of the immune system of the host.

$\beta$-lactamase inhibitors are the prototype of agents without own growth-inhibitory activity in the treatment of bacterial infections. In 1980, the first $\beta$-lactamase inhibitor, clavulanic acid, was introduced into therapy in combination with amoxicillin, thereby efficiently protecting the potent semisynthetic penicillin-derivative from inactivating hydrolysis by the resistance factor. This combination principle proved highly successful and has preserved the value of potent $\beta$-lactams for decades [116]. However, the inhibitory activity of clavulanic acid, as well as of all other $\beta$-lactamase inhibitors in clinical use, is restricted to class A $\beta$-lactamases and to date more than 500 different $\beta$-lactamase types have been described, many of which fall into the structural classes B, C and D. Therefore, it is of interest that several novel $\beta$-lactamase inhibitors with broader inhibition spectra are currently in development [117]. A notable example is NXL104 from Novexel, a diazabicylo(3.2.1.) octanone, which is distinguished by its novel structure, lacking a $\beta$-lactam ring, and a remarkably long deacylation rate. The compound shows broad inhibition of $\beta$-lactamases from class $\mathrm{A}$, including the recently emerging carbapenemase KPC, from class $\mathrm{C}$ and partly from class $\mathrm{D}$, but does not affect class B enzymes [117,118]. NXL104 is currently in Phase II studies in combination with ceftazidime for the treatment of complicated urinary tract and intra-abdominal infections and in Phase I in combination with ceftaroline for the treatment of MRSA infections. It is also interesting that the core structure of this non- $\beta$-lactam seems to offer potential beyond the use as a $\beta$-lactamase inhibitor. For compounds that carry the diazabicylo[3.2.1.] octanone core with additional substituents Novexel reported antibacterial activity against drug-resistant $P$. aeruginosa in a patent application [303]. The company also reported the development of a new anti-Pseudomonas compound with undisclosed structure (NXL105), which acts by inhibiting bacterial transpeptidases involved in cell wall biosynthesis. It is tempting to presume that the diazabicylo[3.2.1.] octanone containing structure is NXL105 and that this core also has transpeptidase inhibitory activity.

Although the principle of protecting an antibiotic by an inhibitor of its corresponding resistance factor proved highly effective in the case of $\beta$-lactams, this concept has found no clinical application beyond this class so far. Efflux pumps have been investigated at Microcide and later Mpex and proof-of principle has been obtained in in vitro studies that their inhibition can substantially lower the MIC for quinolones and other antibiotics, particularly in efflux pump overexpressing strains. Several classes of exploratory inhibitors have been described [10], but clinical investigations have not been initiated so far, probably reflecting the significant obstacles associated with this approach. Generally, pathogens are equipped with a redundant set of efflux pump systems and a single antibiotic is often transported by more than one pump. Also, broad-spectrum efflux pumps possess distinct binding sites for different antibiotic substrates and it is difficult to prevent efflux of a broad range of substrates by a single inhibitor simultaneously. Additional problems of previous inhibitors include unfavorable pharmacokinetics and toxicity [119].

A second approach that relies on agents without growth-inhibitory potential in vitro is the inhibition of bacterial virulence factors. Growing knowledge about the physiology of pathogens and hosts over the last decade has boosted our molecular understanding of the factors that promote bacterial pathogenicity in the course of the infection process. This includes the structures that promote adhesion, colonization and dissemination, the components responsible for cell communication and regulatory functions, the factors that facilitate evasion of the immune system and the machineries for toxin production and excretion. As a result, the recent scientific literature is full of examples suggesting the evaluation of specific virulence factors for future antibacterial therapy and inhibitors have been described that display effects in animal models of infection [120]. However, so far only a few companies have initiated discovery programs in this area, which can probably be attributed to the difficulties attached to this approach. First, the often very narrow activity spectrum of the anticipated drugs due to the often high species-specificity of the pathogenicity factor; second a therapeutic rationale that does not aim at pathogen eradication but rather is synergistic with antibiotic intervention; and finally, obstacles in setting up simple in vitro assays for the measurement of inhibitory activity. Paratek, for instance, is searching for inhibitors of MAR proteins (for multiple adaptation response), a family of transcriptional regulators that control a large stress response regulon in Enterobacteriaceae, 
which promotes antibiotic resistance [121]. Inhibiting induction of this regulon increases the sensitivity of bacteria to antibiotic treatment. Furthermore, P005784 (an inhibitor of ExsA, which is a MAR protein that governs the exotoxin-producing type III secretion system), reduced infectivity of $P$. aeruginosa in mice [122]. Mutabilis is investigating inhibitors of heptosyl transferases involved in the biosynthesis of lipopolysaccharides of Gram-negative bacilli [304] as well as compounds interfering with $\mathrm{D}$-alanylation of lipoteichoic acids in streptococci $[120,123]$. Their DltA inhibitor MUTB-370, part of a series of imidazoloquinoxaline derivatives, reduced the D-alanine content in lipoteichoic acids and possessed an antibacterial effect in a mouse model of systemic $S$. agalactiae infection at $10 \mathrm{mg} / \mathrm{kg}$ [124]. The lower D-alanine level in the bacterial cell wall increases the net negative surface charge and sensitizes the bacteria against the activity of defensins of the innate immune system and against cationic antibiotics.

A rather progressed example of a virulence factor inhibitor is the humanized antibody $\mathrm{Fab}$ fragment KB001. KaloBios is currently evaluating the agent in Phase II for the treatment of $P$. aeruginosa infections. KB001 binds to $\mathrm{PcrV}$, a protein located at the tip of the Type III secretion system and blocks the injection needle, thereby preventing the delivery of exotoxins to host cells [125]. Several further therapeutic antibodies are currently in development, including KBPA101 (Kenta Biotech) targeting the $O$-polysaccharide moiety of $P$. aeruginosa serotype O11, an agent that is being co-developed with a diagnostic test for rapid serotyping; Pagibaximab (Biosynexus) directed against lipoteichoic acids of $S$. aureus and a combination of two antibodies targeting C. diffcile exotoxins A and B (Medarex, now acquired by Bristol-Meyers Squibb) [126-128]. The use of therapeutic monoclonal antibodies or fragments thereof has been very successfully established in other therapeutic areas, especially in cancer and immunosuppressive therapy. They may also represent a useful complement to antibiotic therapy, leading to a more rapid resolution of infections in combination with classical antibiotics.

Other biologicals currently under exploratory investigation for the potential treatment of bacterial infections are endolysins derived from bacteriophages. Endolysins are cell-wall hydrolytic enzymes, which are produced by phages at the terminal stage of the phage lytic cycle. These enzymes cut the peptidoglycan at various positions, and possess glucosaminidase, muramidase, amidase and endopeptidase functions; some enzymes even possess two cleavage functionalities. An interesting feature of endolysins is their very rapid lytic action, which is in principle appealing, because it is also directed against resting cells and bacteria living in biofilm communities $[129,130]$. First, therapeutic effects were demonstrated in bacterial infection models in mice (e.g., during the treatment of S. pneumoniae or Bacillus cereus septicemia) [131], however, several hurdles remain that may prevent systemic application in humans. For example, several endolysins were shown to be immunogenic in rabbits and their half-life is rather short [131].

In principle, it may also be possible to interfere with bacterial infections by stimulating the human immune system such that it more efficiently eliminates the invading pathogen. In particular viral disease immune modulators form the current standard therapy (e.g., recombinant $\alpha$-interferons and nucleoside analogues for hepatitis $B$ as well as pegylated interferons and ribavirin against hepatitis $C$ ). A variety of further immune modulatory agents are currently in development for HCV- and HIV-therapy, including interferons, Toll-like receptor agonists and immunoglobulins [132]. For bacterial infections, this approach is still in its infancy. Several biotechnology companies are performing clinical trials for derivatives of host defense peptides involved in innate immunity. Most of these agents are being evaluated for topical use, the most progressed including omiganan by Migenix/Cutanea, pexiganan by Genaera/ Access Pharmaceuticals and iseganan by Ardea Bioscienses [133]. An advantage of topical application is the largely reduced risk of systemic toxicity, an aspect that is particularly important in immunotherapy because of potentially severe inflammatory responses. However, hFL1-11 (AM-Pharma), a peptide derived from lactoferrin, demonstrated safety during systemic application in hematopoietic stem-cell transplant recipients. Furthermore, IMX-942 (Inimex), a synthetic pentapeptide modeled after innate defence regulator-1, has been applied in Phase I trials by the parenteral route.

It is obvious that most approaches discussed in this section are still a long way from the hospital bed, at least in the antibacterial field and that further investigations are required to assess their efficacy or risk:benefit ratio in this therapeutic sector. It is also important to note that, apart from the broad-spectrum $\beta$-lactamase inhibitors, all agents discussed in 
this paragraph have a narrow activity spectrum that is in many cases restricted to a single bacterial species. The same applies to several of the novel antibiotic classes presented above and further compounds compiled in another recent review [134]. In strong contrast, current medical practice still requires empirical broad-spectrum therapy in order to assure rapid adequate therapy, thereby precluding the use of such agents. The reason is that diagnostic tools still have not developed to the point where rapid, robust and economic assays are available for most of the relevant bacterial species. However, much technical progress has also been achieved in diagnostics, especially in methodologies relying on DNA and RNA amplification and on pathogen identification by MS $[135,136]$. In the medium term we can therefore expect improvements in in vitro diagnostics to impact on the collection of antibacterial agents considered suitable for certain indications. As the time needed for pathogen identification is reduced, as simplified assay technology will support point-of-care diagnostics and as broader application will reduce the costs per assay, antibiotics with limited spectrum coverage will probably become a treatment option [134].

Another principal option is the combination of two active agents with the aim to exploit their synergistic activity or in order to protect them from rapid resistance development. Although the free combination of two or more active antibiotics from different classes is daily business for physicians in the treatment of severe bacterial infections in the clinical setting or in tuberculosis therapy, fixed combinations of two active ingredients are still the exception in the field. Prototypical examples are the combination of diaminopyrimidines (e.g., trimethoprim) with sulfonamides (e.g., sulfamethoxazole) to inhibit two consecutive enzymes in tetrahydrofolate biosynthesis [137] or the streptogramins quinupristin and dalfopristin binding synergistically to adjacent sites of the ribosomal P-site. So far, companies have been rather reluctant of developing combination products of two novel chemical entities due to the additional risks attached to and development efforts required for such an approach (e.g., the necessity of matched pharmacokinetics, the demonstration of superior efficacy of the combination product versus the single ingredients, the increased cost of goods and the increased risk of adverse effects). However, in the light of the shortage of novel broad-spectrum antibiotic classes the commercial values of such combination approaches will probably increase.

\section{Commercial \& regulatory implications}

So far, this article has discussed the scientific challenges and chances of antibacterial drug discovery, including the target selection procedure, the compound sources and the screening process. Economical and regulatory aspects that triggered considerable fluctuations among the companies active in the field are discussed below. Bacterial diseases are predominantly acute illnesses and the corresponding treatment is generally prescribed for a short course therapy. Several highly successful broad-spectrum antibiotics have demonstrated that blockbuster status can also be reached in this field and that it can even persist after patent expiry (e.g., ciprofloxacin and amoxicillin/clavulanic acid). However, it is comparably difficult for antibiotics to reach sales volumes that match those of long-term therapeutics, especially in the light of the reasonable attempts to reduce overall antibiotic usage and with regard to narrow-spectrum agents. On the other hand, the overall costs for the development of an antibacterial agent are in the same range as for drugs for other indications and have increased tremendously over the last two decades (from US $\$ 231$ million in 1987 to US $\$ 800$ million in 2001 , including expenditures for failed programs) [138]. In addition, the antibacterial market is mature and new drugs are confronted with substantial generic competition. The recommendation to preserve novel resistance-breaking agents for the treatment of serious cases, together with the policy of health insurance companies to fund the cheapest available treatment, reduces return on investment further. These factors combined make the risk-adjusted net present value, as a measure of the commercial potential of a product, about ten times less for an antibiotic compared with a muscular-skeletal pain killer [205]. Political and regulatory authorities together with medical and pharmaceutical alliances have been engaged in lively and controversial debates about this dilemma for years $[139,140,206]$ and it bodes well that recent discussions aim at finding reasonable and feasible economic incentives for investors in order to attenuate this commercial imbalance [205].

The design of the clinical studies and the efficacy and safety that a new resistance-breaking antibiotic has to demonstrate in order to obtain regulatory approval is another point to consider. Regulatory requirements have increased continuously and pharmaceutical companies experience uncertainty with respect to the goals that they actually have to meet in order 
to obtain approval of their drugs [141]. The sum of these challenges together with a process of pharmaceutical industry concentration by mergers and acquisitions had led many big players to retreat from antibacterial drug discovery and to redirect their effort to the more profitable therapies of chronic diseases. The field has been left to a handful of big-pharma competitors and a substantial number of biotechnology enterprises [142-144]. As a result, the number of patent applications in the antibacterial field declined substantially [138] along with the number of approved antibiotics [139,141,145]. If we do not want to lose our good therapeutic standard for the treatment of bacterial infections, it is important that we introduce new potent and resistance-breaking drugs into therapy before resistance prevalence of bacteria against the current standard-of-care reaches substantial values and it is currently high time for that. Clear and lasting regulatory guidelines that companies can rely on in their study design must be formulated, the requirements regarding efficacy and safety need to be balanced and achievable and the expenditures necessary to obtain the requested results must be reasonable in order to attract companies back to the antibacterial field. However, it is promising that first big-pharma companies are now showing renewed interest in antibacterial research and are in the process of building up such structures again. They seem to have realized that the development of antibiotics also carries substantial advantages in relation to other therapeutic areas $[139,145,146]$. The overall profiling cascade for assessing the potential of an investigational antibacterial agent is well established and includes standardized in vitro assays for determining antibacterial activity, highly predictive animal models for a broad range of infections and elaborate techniques for metabolic, pharmacokinetic and pharmacodynamic investigations. As a result, in most cases it is possible to judge as early as the preclinical phase whether an investigational antibiotic will have sufficient therapeutic efficacy and tolerability in clinical studies and to predict suitable treatment doses, which even take into account mutation-prevention concentrations. While this early identification of pitfalls and the high predictability cause a comparably high attrition rate in exploratory antibacterial research, the advantage shows at later stages, because the success rate from Investigational New Drug applications (the documentation required to obtain regulatory approval for first studies in man) to market authorization, is in the range of $30 \%$ for anti-infectives compared with $15 \%$ for cardiovascular, cancer and central nervous system therapeutics $[139,146]$. Furthermore, clinical studies for antimicrobials are generally shorter than for most other therapeutic areas due to the shorter treatment courses and corresponding omission of long-term safety studies. Accordingly, regulatory authorities usually require less time for data analysis and for conclusion of the approval process.

\section{Future perspective}

Although the genomics and functional techniques did not directly pay off by providing the naively expected wealth of novel antibacterial lead structures, they have added much to our understanding of bacterial physiology, pathogenicity, pathogen-host interaction, mechanisms of antibiotic action and bacterial resistance development. As a result, our knowledge about the characteristics of a successful antibiotic has considerably expanded and our technical capabilities for determining these requirements have improved in parallel. Thus, in principle, our intellectual and methodological position for discovering novel antibiotics is better than ever and there is no reason to believe that this should not yield new antibacterial classes in the medium-term even against Gram-negative problem pathogens. It is probably also an advantage that the screening strategies employed and the therapeutic options evaluated have noticeably increased in diversity, providing more chances of success. Regarding the sources of antibiotics, it is important to note that the past has shown us that successful antibiotics can, in principle, be found among natural products as well as among synthetic molecules and therefore we should continue to search within both pools of compounds. However, we will need access to new natural products as sources for new leads and we will have to consider the particular physicochemical and structural features required for penetration into bacterial cells and for antibiotic action during synthetic library design and during optimization programs.

On the other hand, there is no reason to hope that we will enter a second 'golden age of antibiotics', where we will discover novel potent and tolerable broad-spectrum antibiotics easily. In addition, some antibiotic resistance mechanisms that have been selected in the bacterial population during the decades of antibiotic treatment, such as efflux pump overexpression or porin reduction, affect available bacterial classes broadly and there is risk that they also impact on novel classes with unrelated mechanisms of action. Therefore, we 
should make the best of the already established classes, even in the light of increasing resistance against these agents. Recent examples have demonstrated that it is still possible to design resistance-breaking properties into well-known antibiotic classes and this option will be further exploited in the future. The need to cover the required bacterial spectrum despite increasing resistance prevalence will probably also lead to a rising necessity for, and acceptance of, narrowspectrum drugs and antibacterial combination therapies, either as combinations of:

- Two active antibiotics that support each other with respect to mechanism of action, spectrum coverage or resistance prevention;

- One antibacterially active ingredient plus one agent without its own growth inhibitory activity that interferes with a corresponding resistance factor;

- An antibiotic together with an immunestimulating or virulence-reducing agent.

Improvements in diagnostics for identification of the causative agent can be expected to increase the number of agents considered suitable for these approaches. In summary, there are still multiple options for discovering novel antibiotics and further antibacterial treatment principles in the future, which together with their rising commercial value in light of increasing medical need will probably attract more of the bigger pharmaceutical companies back to the antibacterial drug discovery field.

\section{Acknowledgements \\ We thank Guido Schiffer (AiCuris, Wuppertal, Germany) and Harald Labischinski (MerLion, Berlin, Germany) for helpful discussions and critically reading the manuscript. \\ Financial \& competing interests disclosure \\ Heike Brötz-Oesterhelt was previously employed at AiCuris. Work on this article was supported by the Deutsche Forschungsgemeinschaft FOR 854. The authors have no other relevant affiliations or financial involvement with any organization or entity with a financial interest in or financial conflict with the sub- ject matter or materials discussed in the manuscript apart from those disclosed. \\ No writing assistance was utilized in the production of this manuscript.}

\section{Executive summary}

\section{New antibiotic classes are rare in progressed stages of antibacterial drug development}

- During the next 5 years no new Gram-negative antibiotic class can be expected to enter the market.

- The Gram-positive pipeline is better filled, but several agents are currently facing problems during late-stage development and registration.

Target-based high-throughput screening proved unsuccessful for antibacterial drug discovery in the way it had been conducted

- Reasons for this lack of success are related to target selection, screening strategies and compound collections.

- Established targets and metabolic pathways are especially valuable and new antibacterial classes can be found that inhibit these targets/pathways without cross-resistance with currently used drugs. Screening strategies that select for cell penetration in addition to target inhibition yield improved hits. Physicochemistry of antibiotics differs from that of drugs in other therapeutic sectors and natural products are favorable in this respect.

- The short timelines assigned to projects in the high-throughput screening era were inappropriate in relation to the substantial optimization requirements of antibacterial leads.

\section{Postgenomic discovery strategies for antibiotics are diverse}

- Interesting starting points for antibacterial drug discovery have been revealed by re-visiting previously abandoned microbial extracts and underexploited natural product classes using modern technologies.

- Rational inhibitor design on the basis of high-resolution target structures and focused compound libraries has yielded new agents with promising antibacterial activity in vitro as well as in infection models.

- Novel representatives of known antibiotic classes demonstrate therapeutic efficiencies even against resistant isolates and form the majority of current late stage development compounds.

\section{Alternative strategies have potential to support the activity of antibiotics}

- Species-specific therapeutic monoclonal antibodies directed against bacterial virulence factors and the first mimics of host defense peptides involved in innate immunity are being evaluated in clinical trials.

- Exploratory approaches include small molecule inhibitors of virulence and resistance factors as well as phage endolysins.

\section{Small spectrum drugs \& combination approaches will gain increased value}

- Current pharmaceutical pipelines contain very few broad-spectrum agents of novel structural classes.

- Medical need due to rising resistance against existing therapies and technical progress in bacterial diagnostics can together be expected to promote acceptance for, and commercial value of, narrow-spectrum agents and combination approaches. 


\section{Bibliography}

Papers of special note have been highlighted as:

- of interest

- of considerable interest

1. Talbot GH, Bradley J, Edwards JE Jr, Gilbert D, Scheld M, Bartlett JG: Bad bugs need drugs: an update on the development pipeline from the Antimicrobial Availability Task Force of the Infectious Diseases Society of America. Clin. Infect. Dis. 42(5), 657-668 (2006).

2. Gould IM: The epidemiology of antibiotic resistance. Int. J. Antimicrob. Agents 32(Suppl. 1), S2-S9 (2008).

3. Nordmann P, Naas T, Fortineau N, Poirel L: Superbugs in the coming new decade; multidrug resistance and prospects for treatment of Staphylococcus aureus, Enterococcus spp. and Pseudomonas aeruginosa in 2010. Curr. Opin. Microbiol. 10(5), 436-440 (2007).

4. Theuretzbacher U: Future antibiotics scenarios: is the tide starting to turn? Int. J. Antimicrob. Agents 34(1), 15-20 (2009).

- Recent overview of current projects in industry pipelines against Gram-positive and Gram-negative bacteria.

5. Giamarellou H, Poulakou G: Multidrugresistant Gram-negative infections: what are the treatment options? Drugs 69(14), 1879-1901 (2009).

6. Souli M, Galani I, Giamarellou H: Emergence of extensively drug-resistant and pandrug-resistant Gram-negative bacilli in Europe. Euro. Surveill. 13(47), (2008).

7. Falagas ME, Rafailidis PI, Matthaiou DK, Virtzili S, Nikita D, Michalopoulos A: Pandrug-resistant Klebsiella pneumoniae, Pseudomonas aeruginosa and Acinetobacter baumannii infections: characteristics and outcome in a series of 28 patients. Int. J. Antimicrob. Agents 32(5), 450-454 (2008).

8. Page MG, Heim J: Prospects for the next anti-Pseudomonas drug. Curr. Opin. Pharmacol. 9(5), 558-565 (2009).

9. Levy SB, Marshall B: Antibacterial resistance worldwide: causes, challenges and responses. Nat. Med. 10 (12 Suppl.), S122-S129 (2004).

10. Lomovskaya O, Zgurskaya HI, Totrov M, Watkins WJ: Waltzing transporters and 'the dance macabre' between humans and bacteria. Nat. Rev. Drug Discov. 6(1), 56-65 (2007).

11. Pages JM, James CE, Winterhalter M: The porin and the permeating antibiotic: a selective diffusion barrier in Gram-negative bacteria. Nat. Rev. Microbiol. 6(12), 893-903 (2008).

12. Sass P, Brötz-Oesterhelt H: Bacterial stress responses to antimicrobial agents. In: Stress Responses in Foodborne Microorganisms. Wong HC (Ed.). Nova Science Publishers, Inc., NY, USA (2010) (In press).
13. Davies J: Resistance redux. Infectious diseases, antibiotic resistance and the future of mankind. EMBO Rep. 9(Suppl. 1), S18-S21 (2008).

14. Woodford N, Livermore DM: Infections caused by Gram-positive bacteria: a review of the global challenge. J. Infect. 59 (Suppl. 1), S4-S16 (2009).

15. Morales G, Picazo JJ, Baos E et al.: Resistance to linezolid is mediated by the $c f r$ gene in the first report of an outbreak of linezolidresistant Staphylococcus aureus. Clin. Infect. Dis. 50(6), 821-825 (2010).

16. Gale EF, Cundliffe E, Reynolds PE, Richmond MH, Waring MJ: The Molecular Basis of Antibiotic Action (2nd Revised Edition). John Wiley \& Sons Ltd., London, UK (1981).

17. Payne DJ, Gwynn MN, Holmes DJ, Pompliano DL: Drugs for bad bugs: confronting the challenges of antibacterial discovery. Nat. Rev. Drug Discov. 6(1), 29-40 (2007).

- Review critically describing the experiences of GlaxoSmithKline with 70 target-based high-throughput screening campaigns.

18. Freiberg C, Brötz-Oesterhelt $\mathrm{H}$, Labischinski H: The impact of transcriptome and proteome analyses on antibiotic drug discovery. Curr. Opin. Microbiol. 7(5), 451-459 (2004).

19. Miller A: Alternate strategies in antibacterial discovery. Presented at: Visiongain Conference on Re-emerging infectious diseases. London, UK, 11-12 December, 2008.

20. Marrakchi H, Dewolf WE Jr, Quinn C et al.: Characterization of Streptococcus pneumoniae enoyl-(acyl-carrier protein) reductase (FabK). Biochem. J. 370 (Pt 3), 1055-1062 (2003).

21. Zhu L, Lin J, Ma J, Cronan JE, Wang H: Triclosan resistance of Pseudomonas aeruginosa PAO1 is due to FabV, a triclosan-resistant enoyl-acyl carrier protein reductase. Antimicrob. Agents Chemother. 54(2), 689-698 (2010).

22. Gallant P, Finn J, Keith D, Wendler P: The identification of quality antibacterial drug discovery targets: a case study with aminoacyl-tRNA synthetases. Expert Opin. Ther. Targets 4, 1-9 (2000).

23. Karlowsky JA, Kaplan N, Hafkin B, Hoban DJ, Zhanel GG: AFN-1252, a FabI inhibitor, demonstrates a Staphylococcusspecific spectrum of activity. Antimicrob. Agents Chemother. 53(8), 3544-3548 (2009).

24. Wang J, Soisson SM, Young K et al.: Platensimycin is a selective FabF inhibitor with potent antibiotic properties. Nature 441(7091), 358-361 (2006).
25. Wang J, Kodali S, Lee SH et al.: Discovery of platencin, a dual FabF and FabH inhibitor with in vivo antibiotic properties. Proc. Natl Acad. Sci. USA 104(18), 7612-7616 (2007).

26. Freiberg C, Brunner NA, Schiffer G et al.: Identification and characterization of the first class of potent bacterial acetyl-CoA carboxylase inhibitors with antibacterial activity. J. Biol. Chem. 279(25), 26066-26073 (2004).

27. Brinster $S$, Lamberet G, Staels B, Trieu-Cuot P, Gruss A, Poyart C: Type II fatty acid synthesis is not a suitable antibiotic target for Gram-positive pathogens. Nature 458(7234), 83-86 (2009).

- Important investigations on the essentiality of fatty acid synthesis under therapeutic conditions.

28. Brötz-Oesterhelt $\mathrm{H}$, Brunner NA: How many modes of action should an antibiotic have? Curr. Opin. Pharmacol. 8(5), 564-573 (2008).

- Instructive review supporting the concept of multiplicity of action for antibiotic therapy.

29. Silver LL: Multi-targeting by monotherapeutic antibacterials. Nat. Rev. Drug Discov. 6(1), 41-55 (2007).

30. Moir DT: Identification of inhibitors of bacterial enoyl-acyl carrier protein reductase. Curr. Drug Targets Infect. Disord. 5(3), 297-305 (2005).

31. Gentry DR, Ingraham KA, Stanhope MJ et al.: Variable sensitivity to bacterial methionyl-tRNA synthetase inhibitors reveals subpopulations of Streptococcus pneumoniae with two distinct methionyl-tRNA synthetase genes. Antimicrob. Agents Chemother. 47(6), 1784-1789 (2003).

32. McDevitt D, Rosenberg M: Exploiting genomics to discover new antibiotics. Trends Microbiol. 9(12), 611-617 (2001).

33. Streker $\mathrm{K}$, Schäfer $\mathrm{T}$, Freiberg $\mathrm{C}$ et al:: In vitro and in vivo validation of ligA and tarI as essential targets in Staphylococcus aureus. Antimicrob. Agents Chemother. 52(12), 4470-4474 (2008).

34. Becker D, Selbach M, Rollenhagen C et al.: Robust Salmonella metabolism limits possibilities for new antimicrobials. Nature 440 (7082), 303-307 (2006).

35. Yin D, Fox B, Lonetto ML et al.: Identification of antimicrobial targets using a comprehensive genomic approach. Pharmacogenomics 5(1), 101-113 (2004).

36. Singh SB, Phillips JW, Wang J: Highly sensitive target-based whole-cell antibacterial discovery strategy by antisense RNA silencing. Curr. Opin. Drug Discov. Devel. 10(2), 160-166 (2007). 
37. Haas M, Beyer D, Gahlmann R, Freiberg C: $\mathrm{YkrB}$ is the main peptide deformylase in Bacillus subtilis, a eubacterium containing two functional peptide deformylases. Microbiology 147(Pt 7), 1783-1791 (2001).

38. Hutter B, Fischer C, Jacobi A, Schaab C, Loferer $\mathrm{H}$ : Panel of Bacillus subtilis reporter strains indicative of various modes of action. Antimicrob. Agents Chemother. 48(7), 2588-2594 (2004).

39. Urban A, Eckermann S, Fast B et al.: Novel whole-cell antibiotic biosensors for compound discovery. Appl. Environ. Microbiol. 73(20), 6436-6443 (2007).

40. Moir DT, Ming D, Opperman T, Schweizer HP, Bowlin TL: A highthroughput, homogeneous, bioluminescent assay for Pseudomonas aeruginosa gyrase inhibitors and other DNA-damaging agents. J. Biomol. Screen. 12(6), 855-864 (2007).

41. von Nussbaum F, Brands M, Hinzen B, Weigand S, Häbich D: Antibacterial natural products in medicinal chemistry - exodus or revival? Angew. Chem. Int. Ed. Engl. 45(31), 5072-5129 (2006).

- Expert review of a variety of chemical strategies and approaches performed to improve the pharmacological profile of antibacterial natural products.

42. O'Shea R, Moser HE: Physicochemical properties of antibacterial compounds: implications for drug discovery. J. Med. Chem. 51(10), 2871-2878 (2008).

- First analysis of the physicochemical requirements of antibiotics separated by Gram-positives, Gram-negatives and Pseudomonas-active compounds.

43. Lipinski CA, Lombardo F, Dominy BW, Feeney PJ: Experimental and computational approaches to estimate solubility and permeability in drug discovery and development settings. Adv. Drug Deliv. Rev. 23(1-3), 3-25 (1997).

44. Albert JS, Blomberg N, Breeze AL et al.: An integrated approach to fragment-based lead generation: philosophy, strategy and case studies from AstraZeneca's drug discovery programmes. Curr. Top. Med. Chem. 7(16), 1600-1629 (2007).

- Examples of the use of fragment-based discovery in distinct disease areas from a company perspective.

45. Abbanat D, Morrow B, Bush K: New agents in development for the treatment of bacterial infections. Curr. Opin. Pharmacol. 8(5), 582-592 (2008).

46. Nicolaou KC, Chen JS, Edmonds DJ, Estrada AA: Recent advances in the chemistry and biology of naturally occurring antibiotics. Angew. Chem. Int. Ed. Engl. 48(4), 660-719 (2009).
- Detailed recent update of chemistry studies of several natural product classes.

47. Clardy J, Fischbach MA, Walsh CT: New antibiotics from bacterial natural products. Nat. Biotechnol. 24(12), 1541-1550 (2006).

48. Butler MS, Buss AD: Natural products the future scaffolds for novel antibiotics? Biochem. Pharmacol. 71(7), 919-929 (2006).

49. Baltz RH: Renaissance in antibacterial discovery from actinomycetes. Curr. Opin. Pharmacol. 8(5), 557-563 (2008).

50. Baltz RH: Highlights of the Annual Meeting of SIM, 2005. J. Ind. Microbiol. Biotechnol. 33, 475 (2006).

51. Nett M, König GM: The chemistry of gliding bacteria. Nat. Prod. Rep. 24(6), 1245-1261 (2007).

52. Muscholl-Silberhorn A, Thiel V, Imhoff JF: Abundance and bioactivity of cultured sponge-associated bacteria from the Mediterranean sea. Microb. Ecol. 55(1), 94-106 (2008).

53. Kaeberlein T, Lewis K, Epstein SS: Isolating "uncultivable" microorganisms in pure culture in a simulated natural environment. Science 296(5570), 1127-1129 (2002).

54. He H, Williamson RT, Shen B et al.: Mannopeptimycins, novel antibacterial glycopeptides from Streptomyces hygroscopicus, LL-AC98. J. Am. Chem. Soc. 124(33), 9729-9736 (2002).

55. Singh MP, Petersen PJ, Weiss WJ et al.: Mannopeptimycins, new cyclic glycopeptide antibiotics produced by Streptomyces hygroscopicus LL-AC98: antibacterial and mechanistic activities. Antimicrob. Agents Chemother. 47(1), 62-69 (2003).

56. Dushin RG, Wang TZ, Sum PE et al:: Hydrophobic acetal and ketal derivatives of mannopeptimycin- $\alpha$ and desmethylhexahydromannopeptimycin- $\alpha$ : semisynthetic glycopeptides with potent activity against Gram-positive bacteria. J. Med. Chem. 47(14), 3487-3490 (2004).

57. Ruzin A, Singh G, Severin A et al.: Mechanism of action of the mannopeptimycins, a novel class of glycopeptide antibiotics active against vancomycin-resistant Gram-positive bacteria. Antimicrob. Agents Chemother. 48(3), 728-738 (2004).

58. Mygind PH, Fischer RL, Schnorr KM et al:: Plectasin is a peptide antibiotic with therapeutic potential from a saprophytic fungus. Nature 437(7061), 975-980 (2005).

59. Schneider T, Sahl HG: An oldie but a goodie - cell wall biosynthesis as antibiotic target pathway. Int. J. Med. Microbiol. 300(2-3), 161-169 (2010).
60. Brinch KS, Sandberg A, Baudoux P et al:: Plectasin shows intracellular activity against Staphylococcus aureus in human THP-1 monocytes and in a mouse peritonitis model. Antimicrob. Agents Chemother. 53(11), 4801-4808 (2009).

61. Torres MK, Draghi DC, Pillar CM et al.: Activity of NZ2114 against Staphylococcal and Streptococcal isolates, including resistant phenotypes. Presented at: 48th Annual Interscience Conference on Antimicrobial Agents and Chemotherapy (ICAAC) and the Infectious Diseases Society of America (IDSA) 46th Annual Meeting DC, USA, 25-28, October 2008 (Poster F1-3962).

62. Andes D, Craig W, Nielsen LA, Kristensen HH: In vivo pharmacodynamic characterization of a novel plectasin antibiotic, NZ2114, in a murine infection model. Antimicrob. Agents Chemother. 53(7), 3003-3009 (2009).

63. Vertesy L, Ehlers E, Kogler $\mathrm{H}$ et al.: Friulimicins: novel lipopeptide antibiotics with peptidoglycan synthesis inhibiting activity from Actinoplanes friuliensis sp. nov. II. Isolation and structural characterization. J. Antibiot. 53(8), 816-827 (2000).

64. Schneider T, Gries K, Josten M et al: : The lipopeptide antibiotic Friulimicin B inhibits cell wall biosynthesis through complex formation with bactoprenol phosphate. Antimicrob. Agents Chemother. 53(4), 1610-1618 (2009).

65. Young K, Jayasuriya H, Ondeyka JG et al.: Discovery of FabH/FabF inhibitors from natural products. Antimicrob. Agents Chemother. 50(2), 519-526 (2006).

66. Lee SH, Shoop W, Micheal B, Felcetto T, Singh S, Wang J: In vivo evaluation of drug lead candidates by intravenous continuous infusion. Nat Protoc. DOI: 10.1038/ nprot.2006.133 (2006).

67. Bandow JE, Brötz H, Leichert LI, Labischinski H, Hecker M: Proteomic approach to understanding antibiotic action. Antimicrob. Agents Chemother. 47(3), 948-955 (2003).

68. Freiberg C, Fischer HP, Brunner NA: Discovering the mechanism of action of novel antibacterial agents through transcriptional profiling of conditional mutants. Antimicrob. Agents Chemother. 49(2), 749-759 (2005).

69. Böddeker N, Bahador G, Gibbs C et al: : Characterization of a novel antibacterial agent that inhibits bacterial translation. RNA 8(9), 1120-1128 (2002).

70. Brötz-Oesterhelt H, Bandow JE, Labischinski $\mathrm{H}$ : Bacterial proteomics and its role in antibacterial drug discovery. Mass Spectrom. Rev. 24(4), 549-565 (2005). 
71. Lee BG, Park EY, Jeon H et al:: Structures of $\mathrm{ClpP}$ in complex with a novel class of antibiotics reveal its activation mechanism. Nat. Struct. Mol. Biol. 17, 471-478 (2010).

72. Freiberg C, Pohlmann J, Nell PG et al.: Novel bacterial acetyl coenzyme A carboxylase inhibitors with antibiotic efficacy in vivo. Antimicrob. Agents Chemother. 50(8), 2707-2712 (2006).

73. Hinzen B, Raddatz S, Paulsen $\mathrm{H}$ et al: Medicinal chemistry optimization of acyldepsipeptides of the enopeptin class antibiotics. ChemMedChem. 1(7), 689-693 (2006).

74. Brands M, Endermann R, Gahlmann R, Kruger J, Raddatz S: Dihydropyrimidinones - a new class of anti-staphylococcal antibiotics. Bioorg. Med. Chem. Lett. 13(2), 241-245 (2003).

75. Debono M, Abbott BJ, Molloy RM et al.: Enzymatic and chemical modifications of lipopeptide antibiotic A21978C: the synthesis and evaluation of daptomycin (LY146032). J. Antibiot. 41(8), 1093-1105 (1988).

76. Oleson FB Jr, Berman CL, Kirkpatrick JB, Regan KS, Lai JJ, Tally FP: Once-daily dosing in dogs optimizes daptomycin safety. Antimicrob. Agents Chemother. 44(11), 2948-2953 (2000).

77. Cavalleri B, Pagani H, Volpe G, Selva E, Parenti F: A-16686, a new antibiotic from Actinoplanes. I. Fermentation, isolation and preliminary physico-chemical characteristics. J. Antibiot. 37(4), 309-317 (1984).

78. Fang X, Nam J, Shin D, Rew Y, Boger DL, Walker S: Functional and biochemical analysis of a key series of ramoplanin analogues. Bioorg. Med. Chem. Lett. 19(21), 6189-6191 (2009).

79. Schlünzen F, Pyetan E, Fucini P, Yonath A, Harms JM: Inhibition of peptide bond formation by pleuromutilins: the structure of the 50 S ribosomal subunit from Deinococcus radiodurans in complex with tiamulin. Mol. Microbiol. 54(5), 1287-1294 (2004).

80. Novak R, Shlaes DM: The pleuromutilin antibiotics: a new class for human use. Curr. Opin. Investig. Drugs 11(2), 182-191 (2010).

81. Barker JJ: Antibacterial drug discovery and structure-based design. Drug Discov. Today 11(9-10), 391-404 (2006).

82. Wimberly BT: The use of ribosomal crystal structures in antibiotic drug design. Curr. Opin. Investig. Drugs 10(8), 750-765 (2009).

83. Anderson AC: The process of structure-based drug design. Chem. Biol. 10(9), 787-797 (2003).

84. Congreve M, Murray CW, Blundell TL: Structural biology and drug discovery. Drug Discov. Today 10(13), 895-907 (2005).
85. Wishart D: NMR spectroscopy and protein structure determination: applications to drug discovery and development. Curr. Pharm. Biotechnol. 6(2), 105-120 (2005).

86. Villoutreix BO, Eudes R, Miteva MA: Structure-based virtual ligand screening: recent success stories. Comb. Chem. High Throughput. Screen. 12(10), 1000-1016 (2009).

87. Peppard WJ, Schuenke CD: Iclaprim, a diaminopyrimidine dihydrofolate reductase inhibitor for the potential treatment of antibiotic-resistant staphylococcal infections. Curr. Opin. Investig. Drugs 9(2), 210-225 (2008).

88. Dale GE, Broger C, D’Arcy A et al.: A single amino acid substitution in Staphylococcus aureus dihydrofolate reductase determines trimethoprim resistance. J. Mol. Biol. 266(1), 23-30 (1997).

89. Schneider P, Hawser S, Islam K: Iclaprim, a novel diaminopyrimidine with potent activity on trimethoprim sensitive and resistant bacteria. Bioorg. Med. Chem. Lett. 13(23), 4217-4221 (2003).

90. Oefner C, Bandera M, Haldimann A et al.: Increased hydrophobic interactions of iclaprim with Staphylococcus aureus dihydrofolate reductase are responsible for the increase in affinity and antibacterial activity. J. Antimicrob. Chemother. 63(4), 687-698 (2009).

91. Ippolito J, Wang D, Chen S et al.: Novel antibiotic classes to treat Gram-negative infections. Presented at: 49th Annual Interscience Conference on Antimicrobial Agents and Chemotherapy (ICAAC). CA, USA, 12-15 September 2009 (Poster F2-861).

92. Adams DW, Errington J: Bacterial cell division: assembly, maintenance and disassembly of the $\mathrm{Z}$ ring. Nat. Rev. Microbiol. 7(9), 642-653 (2009).

93. Ohashi Y, Chijiiwa Y, Suzuki K et al.: The lethal effect of a benzamide derivative, 3-methoxybenzamide, can be suppressed by mutations within a cell division gene, $f t s Z$, in Bacillus subtilis. J. Bacteriol. 181(4), 1348-1351 (1999).

94. Czaplewski LG, Collins I, Boyd EA et al.: Antibacterial alkoxybenzamide inhibitors of the essential bacterial cell division protein FtsZ. Bioorg. Med. Chem. Lett. 19(2), 524-527 (2009).

95. Haydon DJ, Stokes NR, Ure R et al:: An inhibitor of Fts $Z$ with potent and selective anti-staphylococcal activity. Science 321(5896), 1673-1675 (2008).

96. Schulz MN, Hubbard RE: Recent progress in fragment-based lead discovery. Curr. Opin. Pharmacol. 9(5), 615-621 (2009).
97. Sherer B, Hauck S, Bist S et al.: Novel DNA gyrase inhibitors: improvement of pyrrolamide antibacterial activity by 3-fluoropiperidine linkers. Presented at: 49th Annual Interscience Conference on Antimicrobial Agents and Chemotherapy (ICAAC). CA, USA, 12-15 September 2009, (Poster F1-1977).

98. Uria-Nickelsen M, Illingworth RN, Blodgett A, Bryant J, Eakin E: Novel DNA gyrase inhibitors: microbiological characterization and in vivo efficacy of 3-fluoropiperidine pyrrolamides. Presented at: 49th Annual Interscience Conference on Antimicrobial Agents and Chemotherapy (ICAAC). CA, USA, 12-15 September 2009 (Poster F1-1978).

99. Hebeisen P, Heinze-Krauss I, Angehrn P, Hohl P, Page MG, Then RL: In vitro and in vivo properties of Ro 63-9141, a novel broad-spectrum cephalosporin with activity against methicillin-resistant staphylococci. Antimicrob. Agents Chemother. 45(3), 825-836 (2001).

100. Davies TA, Page MG, Shang W, Andrew T, Kania M, Bush K: Binding of ceftobiprole and comparators to the penicillin-binding proteins of Escherichia coli, Pseudomonas aeruginosa, Staphylococcus aureus, and Streptococcus pneumoniae. Antimicrob. Agents Chemother. 51(7), 2621-2624 (2007).

101. Hawser S, Lociuro S, Islam K: Dihydrofolate reductase inhibitors as antibacterial agents. Biochem. Pharmacol. 71(7), 941-948 (2006).

102. Shaw KJ, Poppe $S$, Schaadt R et al.: In vitro activity of TR-700, the antibacterial moiety of the prodrug TR-701, against linezolidresistant strains. Antimicrob. Agents Chemother. 52(12), 4442-4447 (2008).

103. Olson MW, Ruzin A, Feyfant E, Rush TS 3rd, O'Connell J, Bradford PA: Functional, biophysical, and structural bases for antibacterial activity of tigecycline. Antimicrob. Agents Chemother. 50(6), 2156-2166 (2006).

104. Berisio R, Harms J, Schluenzen F et al.: Structural insight into the antibiotic action of telithromycin against resistant mutants. J. Bacteriol. 185(14), 4276-4279 (2003).

105. Kim SJ, Cegelski L, Stueber D et al.: Oritavancin exhibits dual mode of action to inhibit cell-wall biosynthesis in Staphylococcus aureus. J. Mol. Biol. 377(1), 281-293 (2008).

106. Higgins DL, Chang R, Debabov DV et al.: Telavancin, a multifunctional lipoglycopeptide, disrupts both cell wall synthesis and cell membrane integrity in methicillin-resistant Staphylococcus aureus. Antimicrob. Agents Chemother. 49(3), 1127-1134 (2005). 
107. Petersen PJ, Jacobus NV, Weiss WJ, Sum PE, Testa RT: In vitro and in vivo antibacterial activities of a novel glycylcycline, the 9-t-butylglycylamido derivative of minocycline (GAR-936). Antimicrob. Agents Chemother. 43(4), 738-744 (1999).

108. Weir S, Macone A, Donatelli J et al.: The activity of PTK 0796 against tetracycline resistance. Presented at: 43th Annual Interscience Conference on Antimicrobial Agents and Chemotherapy (ICAAC). IL, USA, 13-17 September 2010 (Poster F-752).

109. Page MG, Heim J: New molecules from old classes: revisiting the development of $\beta$-lactams. IDrugs 12(9), 561-565 (2009).

110. Bowker KE, Noel AR, Walsh TR, MacGowan AP: In-vitro potency of a Siderophore Monobactam BAL30072 (BAL) against Gram-negative bacilli (GNB) with defined $\beta$-lactamase enzymes. Presented at: 49th Annual Interscience Conference on Antimicrobial Agents and Chemotherapy (ICAAC). CA, USA, 12-15 September 2009 (Poster F1-1481).

111. Endimiani A, Hujer KM, Hujer AM et al.: ACHN-490, a neoglycoside with potent in vitro activity against multidrug-resistant Klebsiella pneumoniae isolates. Antimicrob. Agents Chemother. 53(10), 4504-4507 (2009).

112. Aggen JB, Armstrong ES, Goldblum AA et al: : Synthesis, structure and in vitro activity of the neoglycoside ACHN-490. Presented at: 49th Annual Interscience Conference on Antimicrobial Agents and Chemotherapy (ICAAC). CA, USA, 12-15 September 2009 (Poster F1-840).

113. Almer LS, Hoffrage JB, Keller EL, Flamm RK, Shortridge VD: In vitro and bactericidal activities of ABT-492, a novel fluoroquinolone, against Gram-positive and Gram-negative organisms. Antimicrob. Agents Chemother. 48(7), 2771-2777 (2004).

114. Jacobs MR, Bajaksouzian S, Windau A et al.: In vitro activity of the new quinolone WCK 771 against staphylococci. Antimicrob. Agents Chemother. 48(9), 3338-3342 (2004).

115. Higgins PG, Stubbings W, Wisplinghoff $H$, Seifert H: Activity of the investigational fluoroquinolone finafloxacin against ciprofloxacin-sensitive and -resistant Acinetobacter baumannii. Antimicrob. Agents Chemother. 54(4), 1613-1615 (2010).

116. Ball P: The clinical development and launch of amoxicillin/clavulanate for the treatment of a range of community-acquired infections. Int. J. Antimicrob. Agents 30 (Suppl. 2), S113-S117 (2007).

117. Drawz SM, Bonomo RA: Three decades of $\beta$-lactamase inhibitors. Clin. Microbiol. Rev. 23(1), 160-201 (2010).
118. Stachyra T, Levasseur P, Pechereau MC et al. In vitro activity of the $\beta$-lactamase inhibitor NXL104 against KPC-2 carbapenemase and Enterobacteriaceae expressing KPC carbapenemases. J. Antimicrob. Chemother. 64(2), 326-329 (2009).

119. Lomovskaya O, Bostian KA: Practical applications and feasibility of efflux pump inhibitors in the clinic - a vision for applied use. Biochem. Pharmacol. 71(7), 910-918 (2006).

120. Escaich S: Antivirulence as a new antibacterial approach for chemotherapy. Curr. Opin. Chem. Biol. 12(4), 400-408 (2008).

121. Barbosa TM, Levy SB: Differential expression of over 60 chromosomal genes in Escherichia coli by constitutive expression of MarA. J. Bacteriol. 182(12), 3467-3474 (2000).

122. Gay R, Garrity-Ryan LK, Kim OK et al.: Efficacy of MAR inhibitors in a Pseudomonas aeruginosa pneumonia model. Presented at: 48th Annual Interscience Conference on Antimicrobial Agents and Chemotherapy (ICAAC) and the Infectious Diseases Society of America (IDSA) 46th Annual Meeting. DC, USA, 25-28 October 2008 (Poster F1-3958).

123. Cox KH, Ruiz-Bustos E, Courtney HS et al.: Inactivation of DltA modulates virulence factor expression in Streptococcus pyogenes. PLoS One 4(4), E5366 (2009).

124. Moreau F, Vongsouthi V, Prouvensier V et al.: Discovery of new Gram-positive antivirulence drugs: characterization of novel DltA inhibitors. Presented at: 47th Annual Interscience Conference on Antimicrobial Agents and Chemotherapy (ICAAC). IL, USA, 17-20 September 2007 (Poster F2-957).

125. Baer M, Sawa T, Flynn P et al.: An engineered human antibody fab fragment specific for Pseudomonas aeruginosa PcrV antigen has potent antibacterial activity. Infect. Immun. 77(3), 1083-1090 (2009).

126. Lazar H, Horn MP, Zuercher AW et al:: Pharmacokinetics and safety profile of the human anti-Pseudomonas aeruginosa serotype O11 immunoglobulin M monoclonal antibody KBPA-101 in healthy volunteers. Antimicrob. Agents Chemother. 53(8), 3442-3446 (2009).

127. Weisman LE, Thackray HM, Garcia-Prats JA et al.: Phase I/II doubleblind, placebo-controlled, dose escalation, safety, and pharmacokinetic study of pagibaximab (BSYX-A110), an antistaphylococcal monoclonal antibody for the prevention of staphylococcal bloodstream infections, in very-low-birthweight neonates. Antimicrob. Agents Chemother. 53(7), 2879-2886 (2009).
128. Lowy I, Molrine DC, Leav BA et al.: Treatment with monoclonal antibodies against Clostridium difficile toxins. N. Engl. J. Med. 362(3), 197-205 (2010).

129. Loeffler JM, Nelson D, Fischetti VA: Rapid killing of Streptococcus pneumoniae with a bacteriophage cell wall hydrolase. Science 294(5549), 2170-2172 (2001).

130. Sass P, Bierbaum G: Lytic activity of recombinant bacteriophage phi11 and phi12 endolysins on whole cells and biofilms of Staphylococcus aureus. Appl. Environ. Microbiol 73(1), 347-352 (2007).

131. Fischetti VA: Bacteriophage lysins as effective antibacterials. Curr. Opin. Microbiol 11(5), 393-400 (2008).

132. Hamill P, Brown K, Jenssen H, Hancock RE: Novel anti-infectives: is host defence the answer? Curr. Opin. Biotechnol. 19(6), 628-636 (2008).

133. Easton DM, Nijnik A, Mayer ML, Hancock RE: Potential of immunomodulatory host defense peptides as novel anti-infectives. Trends Biotechnol. 27(10), 582-590 (2009).

134. Then RL, Sahl HG: Anti-infective strategies of the future: is there room for species-specific antibacterial agents? Curr. Pharm. Des 16(5), 555-566 (2010).

135. Malhotra-Kumar S, Haccuria K, Michiels M et al:: Current trends in rapid diagnostics for methicillin-resistant Staphylococcus aureus and glycopeptide-resistant enterococcus species. J. Clin. Microbiol. 46(5), 1577-1587 (2008).

136. Sauer S, Kliem M: Mass spectrometry tools for the classification and identification of bacteria. Nat. Rev. Microbiol. 8(1), 74-82 (2010).

137. Libecco JA, Powell KR: Trimethoprim/ sulfamethoxazole: clinical update. Pediatr. Rev. 25(11), 375-380 (2004).

138. Katz ML, Mueller LV, Polyakov M, Weinstock SF: Where have all the antibiotic patents gone? Nat. Biotechnol. 24(12), 1529-1531 (2006).

139. Powers JH: Antimicrobial drug development - the past, the present, and the future. Clin. Microbiol. Infect. 10(Suppl. 4), 23-31 (2004).

140. Nathan C, Goldberg FM: Outlook: the profit problem in antibiotic R\&D. Nat. Rev. Drug Discov. 4(11), 887-891 (2005).

141. Boucher HW, Talbot GH, Bradley JS et al.: Bad bugs, no drugs: no ESKAPE! An update from the Infectious Diseases Society of America. Clin. Infect. Dis. 48(1), 1-12 (2009).

142. Fox JL: The business of developing antibacterials. Nat. Biotechnol. 24(12), 1521-1528 (2006). 
143. Boggs AF, Miller GH: Antibacterial drug discovery: is small pharma the solution? Clin. Microbiol. Infect. 10(Suppl. 4), 32-36 (2004).

144. Projan SJ: Why is big pharma getting out of antibacterial drug discovery? Curr. Opin. Microbiol. 6(5), 427-430 (2003).

145. Spellberg B, Powers JH, Brass EP, Miller LG, Edwards JE Jr: Trends in antimicrobial drug development: implications for the future. Clin. Infect. Dis. 38(9), 1279-1286 (2004).

146. Bush K: Antibacterial drug discovery in the 21st century. Clin. Microbiol. Infect. 10(Suppl. 4), 10-17 (2004).

\section{Websites}

201. European Antimicrobial Resistance Surveillance System (EARSS) annual report (2008)

www. rivm.nl/earss/result/Monitoring reports/Annual_reports.jsp
- Recent update of the bacterial resistance situation in Europe.

202. Report from the American Academy of Microbiology (AAM): Antibiotic resistance: an ecological perspective on an old problem (2009) http://academy. asm. org/images/stories/ documents/antibioticresistance. pdf

- Recent comprehensive expert report describing the ecology of bacterial resistance development and suggesting a variety of measures to counteract its spread.

203. National Center for Biotechnology Information (NCBI) (2010)

www.ncbi.nlm.nih.gov/genomes/Complete. html

204. RCSB - Protein Data Bank (2010) www.rcsb.org/pdb/home/home.do
205. Conference report: innovative incentives for effective antibacterials (2009)

www. se2009. eu/polopoly_fs/1.

25861!menu/standard/file/Antibacterials5. pdf

206. IDSA policy report: Bad Bugs, No Drugs: As Antibiotic R\&D Stagnates, a Public Health Crisis Brews (2004) http://www.idsociety.org/WorkArea/linkit.as px?LinkIdentifier $=$ id \&ItemID $=5554$

\section{Patents}

301. AMERICAN CYANAMID CO: US3495004 (1970).

302. BIOSEARCH ITALIA SPA, ITALY: EP-976394 (2000).

303. NOVEXEL: WO/2008/142285 (2008).

304. MUTABILIS: WO/2006/058796 (2006). 